"فاعلية استخدام استراتيجية ماكفرلاند المدعومة بالواقع الافتراضي في تدريس منهج الاقتصاد على تنمية مهارات اتخاذ القرار والذات الاستثمارية لاى طلاب المدارس الثانوية الفندقية"

$$
\text { بحث مقدم إلى }
$$

المؤتمر العلمي الثالث عشر لكلية التربية جامعة طنطا في الفترة من ؟ -ه

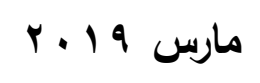

$$
\text { اعداد د/ فاطمة فاروق الثرقاوي }
$$

كلية التربية جامعه طنطا

$$
\text { ملخص البحث }
$$

استهذف البحث الحالي قياس فاعلية استراتيجية ماكفرلاند الددعومة بالواقع

الافتراضي في تدريس احدى وحدات منهج الاقتصاد للصف الثالث الثانوي الفندقي،

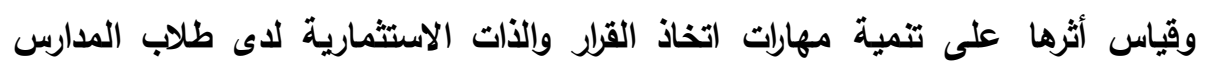

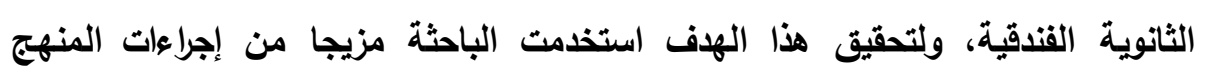

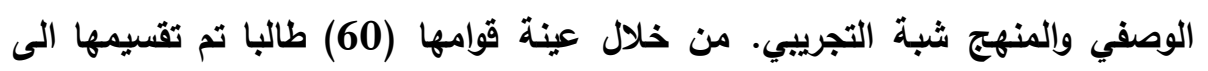
(30) طالب كمجوعة تجريبية (30) طالب كمجموعة ضابطة، ولقياس فاعلية استراتيجية

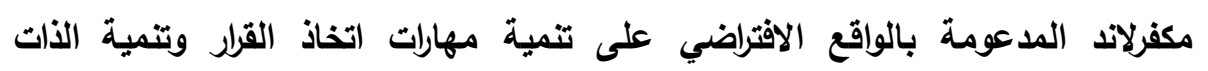

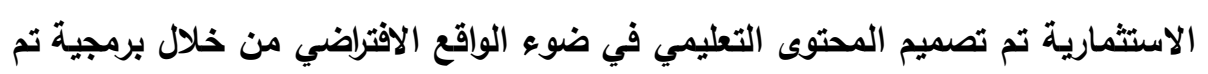

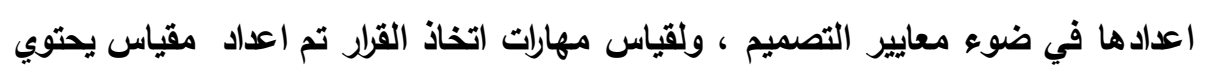
على (V) مهارات مرتبط بكل مهارة (T) عبارات فرعية تم توزيعها بين عبارات إيجابية

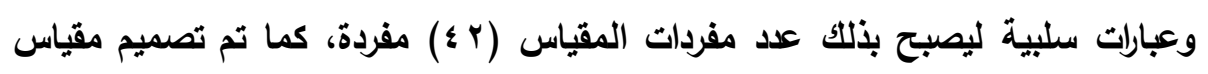

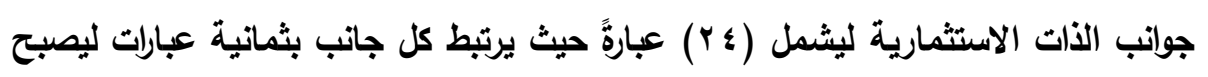


بذلك عدد مفردات المقياس (؟Y) مفردة، وقث تم توزيع العبارات على الجوانب الثلاثة لمقياس الأت الاستثمارية(الاقتصادي - الاجتماعي - الإداري). وقث أظهرت نتيجة البحث لحالي فاعلية استراتيجية ماكفرلاند المدعومة بالواقع الافتراضي في تتمية مهارات اتخاذ القلار وتتمية الذات الاستثمارية لاى المجموعة التجريبية. واستتاداً الى هذه النتيجة قدم البحث مجموعة من التوصيات لتعميم استخدام الواقع الافتراضي في التدريس والتدريب، وربط التكنولوجيا بتعليم المهارات، وتدعيم استخدام استراتيجيات تدريسية تساعد على تنمية مهارات اتخاذ القرار، والاستفادة من الواقع الافتراضي في تطوير المقريات الدارية للمدارس الثانوية القنية بصفة عامة، والفنية التجارية والفندقية بصفة خاصة. الكلمات الافتتاحية: استراتيجية مكفرلاند ، الواقع الافتراضي، مهارات اتخاذ القرار، الأات الاستثمارية

يع العصر الحالي عصر التكنولوجيا والسماوات المفتوحة حيث أصبحت التكنولوجيا وتطبيقاتها في كل المجالات، ومن بينها التعليم والتعلم، وفى وسط هذا التلاحق المعرفي أصبحت المعرفة كيان من التراكمية الخلاقة مما حذا بالتربويين إلى استخدام التكنولوجيا حتى يمكن ملاحقة هذا الانفجار المعرفي. ولما كنا في عصر أصبح الواقع الاقتراضي وتطبيقاته مخترقا لكل الميادين والمجالات حيث أصبح محاكيا للواقع الحقيقي في كثير من الأحيان مما دفع بالمتخصصين في مجال التربية بصفه عامة، وإلمناهج وطرق التدريس بصفة خاصة إلى محاولة الاستفادة منه باستحاث طرق وتقتيات جليدة تتيح للمتعلم فرص المشاركة الفعالة بعيدا عن الحفظ والتلقين حيث يمكنه انتاج إطار معرفيا مغايرا ومتجددا يساعد في النهاية على التفكير بشكل أفضل وتتمية جواتب شخصيته المتعدة. 
ومن هنا اذ كان الواقع الافتراضي وتطبيقاته يشكل جزعا أساسيا من مقومات التربية الحليثة، ومنها المناهج وطرق التريس، فلا يمكن أن نظل بمنأى عن هذا التطور وان نكف أيدينا بعيدا، وإنما أصبح لزاما أن نستقيا بتلك التقتيات في تقيم معرفة (بداعية مختلفة تساعد الطلاب على اتخاذ القرارات بشكل صائب، ويصبح لليهم تقدير لذواتهم بصفة عامة ولذواتهم الخلاقة والمبدعة بصفة خاصة(Fernandez.,2017) . ولقد أشارت بعض من البحوث والدراسات السابقة منها: دراسة خليفه(r ا ب ؟)، ودراسة عويد ( 2016)، والتي اشارت إلى أهمية اعادة النظر في طرق التدريس المستخدمة القائمة على التعلم البنكي، والاستظهار دون فهم ومن ثم اعاده النظر في طرق التريس عامة، وفى المعرفة المكتسبة وما يرتبط بها من مهارات بصفة خاصة، وهنا ظهر الواقع الافتراضي وتطبيقاته كداعم قوى في تقيم طرق واستراتيجيات التدريس بشكل مختلف، ويالتالي أصبح الهذف الاساسي للتعلم القائم على تطبيقات الواقع الافتراضي هو تجاوز ما كان متعارف عليه من المعرفة الرقمية الافتراضية، كما اثار(Yiyo,O.Cai, 2017)، حيث غذا التعلم المرتبط بالتكنولوجيا التفاعلية هدفا في حد ذاته، ووسيلة لتنمية مهارات التفكير بصفه عامه، ومهارات التفكير الإبداعي وما وراء المعرفة واتخاذ القرار بصفة خاصة.

فالتّريس باستخلام الواقع الافتراضي يعطى التعلم مغني مختلف، ويساعد في اكتساب الحقائق وإلمفاهيم والمبادئ والتعميمات عبر شاشة الحاسوب في شكل نصوص وصوت وصورة وحركة وغيرها من تقتيات استخدام الواقع الافتراضي في التّريس، ومن ثم

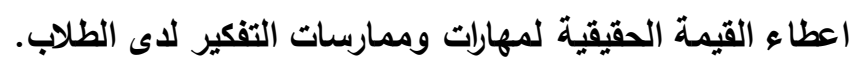
ولعل اهتمام البحث الحالي بالتفكير بصفة عامة، ومهارات ما وراء المعرفة، خاصة مهارات اتخاذ القرار جاء كاستجابة ملحة لما يفرضه الواقع الحالي الأي نحيا فيه، ونعد جزعا منه، ومن ثم التروي واعادة هيكلة الأمور، وطرح البدائل، وانتقاء البديل المناسب، والوصول إلى القرار الصحيح أصبح من الأمور الهامة التي تلقى بظلالها على 
اهتمامات التريويين بصفة عامة، والمتخصصين على وجه الدقة في مجال المناهج وطرق التدريس.

ولقد جاء الواقع الافتراضي كمخل مهم في تعليم الطلاب مهارات اتخاذ القرار، وتقدير جواتب الذات لايهم، ولما كانت مادة الاقتصاد في عرضها لكثير من النظريات والاشكاليات انما يعد هذفا اصيلا من اهداف تدريسها هو قرة الطلاب على اتخاذ القراد وتتمية جوانب الذات الاستثمارية لليهم.

ولما كان واقع تدريس العلوم التجارية يثير إلى استخذام المعلمين لاستراتيجيات تدريسية تقليدية تتمى الحفظ والاستظهار، وهذا ما اشارات اليه دراسة السلاموني (2014)، ودراسة العرنوسي (2011 )، وفي ضوء الصحوة المعرفية القائمة على تطبيقات الواقع الافتراضي، فإن استخدام استراتيجيات تدريسية حليثة تتمى مهارات التفكير ما وراء المعرفي، ومهارات اتخاذ القرار بثكل خاص أصبح ذو أهمية كبيرة، ومن ثم فان استخدام استراتيجية ماكفرلاند في تدريس مادة الاقتصاد مدعومة بتطبيقات الواقع الافتراضي أصبح ضرورة ملحة حيث جاء تعليم الطلاب مهارات اتخاذ القزار، وتتمية جواتب الذات بهاف تشجيع روح التساؤل والبحث والتقصي، وعدم اخذ الأمور على علتها، ويالتالي توسيع الافاق العلمية للطلاب وابعادهم عن الرؤى الضيقة والانطلاق نحو مجالات عقليه أوسع وأرحب، ومن ثم البعد عن التبعية والاستهواء بما يتوافق مع أهداف تدريس مادة الاقتصاد بالمرحلة الثانوية القنية.

وثمة صلة وثيقة بين استخدام استراتيجية ماكفرلاند المدعومة بتطبيقات الواقع

الافتراضي ويين تتمية مهارات اتخاذ القرار، وتنمية جوانب الأت المختلفة وهذا ما اشارت اليه دراسة سويد (2013)، ودراسة الزيدات" (2015)، دراسة مايكل (2016) تلك الدراسات التي أكلت على أن استخدام الواقع الافتراضي وتطبيقاته كداعم لاستراتيجيات تدريس التفكير ومنها استراتيجية ماكفرلاند يسهم بثكل كبير في تنمية مهارات اتخاذ القزار، وتتمية جواتب الذات المختلفة لاى طلاب المرحلة الثانوية الفتية، كما أن نتائج البحوث والدراسات السابقة في مجال تدريس العلوم التجارية بصفة عامة ، وفى مجال 
تدريس الاقتصاد بصفة خاصة ، ومنها دراسة رشوان (2016 ) ) ، ودراسة عواد (2017) وغيرها من الدراسات التي أشارت إلى دور الواقع الافتراضي وتطبيقاته الداعمة لاستراتيجيات تعليم التفكير في تتمية مهارات اتخاذ القرار، وتقدير جواتب الأت حيث يساعد الطلاب في اكتساب روح التساؤل ، والنقاّ ، والاستقصاء ، وطرح البدائل ، واعطاء القيمة والقدر المناسب لذواتهز ، وايضا الاهتمام العالمي و المحلى بضرورة استخدام تطبيقات الواقع الافتراضي في التدريس حتى أصبح في كل مدرسة غرفة ومعمل خاص يسمى " غرفة مناهل المعرفة " ل

وكذلك الاتجاه المتزليد في تدريس العلوم التجارية نحو استخدام الواقع الاقتراضي وتطبيقاته في تدريس مادة الاقتصاد ، وتوصيات مؤتمر الصين للتعلم والتدريب (2012 )، بإدراج تكنولوجيا المعلومات والواقع الافتراضي في التعليم والتدريب في المجال القني والتقتي من اجل التعبير عن التحولات التي تحلث في سوق العمل، توصيات مؤتمر شرم الثيخ لتطوير العملية التعليمية (2016) ، والتي اقرت تظوير منظومة التعليم القني وحثت على ضرورة وضع الأطر وآليات التحفيز والتشجيع لتحقيق التوأمة بين الأطراف المعنية بالتخطيط واعداد المناهج وسوق العمل ، توصيات مؤتمر الكويت (2017) والتي أكلت على تطوير العملية التعليمية في ضوء المستحثثات التكنولوجية والاتجاهات الحدثة في التدريس والتي تساعد على تنمية مهارات التفكير واتخاذ القرار والاتجاه نحو تنمية الذات للمتعلم، يضاف إلى ذلك روئه مصر القومية (2030 ) التي تؤكد على ضرورة وجود جيل واعى من الشباب قادر على التفكير بشكل جيد ، ولديه القدرة على اتخاذ القرار المناسب ، وتطوير برامج أعداد المعلم للتوافق مع المتغيرات التكنولوجية والأساليب الحليثة التي تشجع المتعلم على التفكير وحل المشكلات بأسلوب علمي ، بما بحقق التق مخرجات تعليمية قادرة على الوفاء بمتطلبات التتمية المستدامة ومن هنا جاء البحث الحالي في محاولة للتعرف على مدى فاعلية استخدام استراتيجية ماكفرلاند المدعومة بالواقع الافتراضي في تدريس مادة الاقتصاد على تنمية مهارات اتخاذ القرار، وجوانب الاتات الاستثمارية لاى طلاب المدارس الثانوية القنية . 


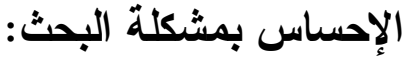

شعرت الباحثة بمشكلة البحث من خلال عدد من الدلائل منها:

1 - الفجوة بين مخرجات منظومة التعليم الفني والتتريب المهني ومتطلبات سوق

العمل مما أدى الى ضعف ثقة المجتمع بالتعليم الفني بصفة عامة والتجاري بصفة وخاصة، واعتباره عبئا على منظومة التعليم وخطط التمية المستامة (مؤتمر شرم الثيخ، (2016).

ץ - نتائج الداسات السابقة التي أكلت على ضرورة تطوير مناهج التعليم التجاري بما يتناسب مع احتياجات ومتطبات سوق العمل في ظل التحليات المعاصرة التي يواجها هذا النوع من التعليم منها: دراسة الثرقاوي (2006) ، دراسة نخلة (2013) وكنلك توصيات مؤتمر شرم الثيخ لتطوير منظومة التعليم الفني (2017) ، الذي اكد على ضرورة ريط التعليم الفني والتريب المهني بمؤسسات الإنتاج وتطوير مناهجه وتأهيل معلميه واستخذام التنريب المهني الذي يتوافق

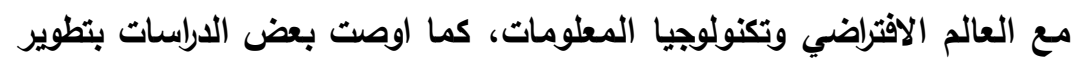

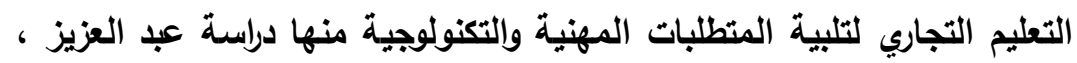
فوده (2014) ، دراسة السلاموني (2014) ،دراسة فودة (2016 ).

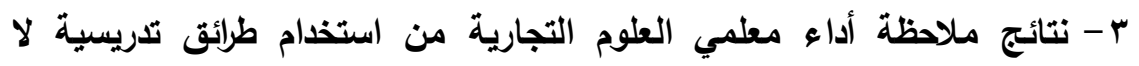
تتناسب مع طييعة مقرات العلوم التجارية، ومنها مقر الاقتصاد لطلاب

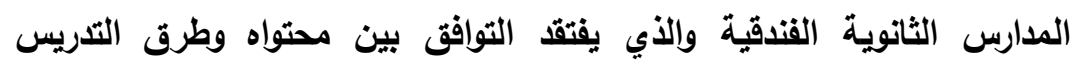

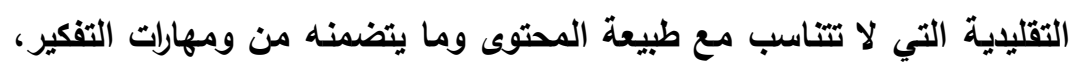

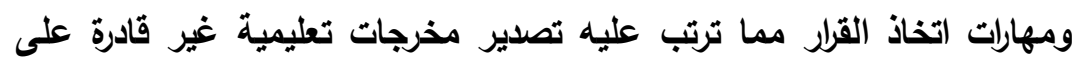

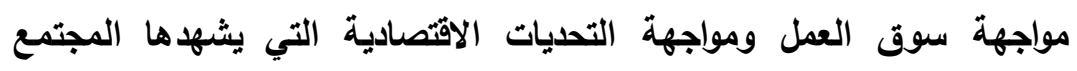
المصري في الوقت الحالي. 
تحلدث مشكلة البحث الحالي في افتقار مناهج التعليم التجاري لاستخدام

استراتيجيات تدريسية تساعد على تنمية مهارات التفكير لدى الطلاب والتي بلورها تساعدهم على تنمية مهارات اتخاذ القرار وتتمية الأات الاستثمارية لاى الطلاب والتي تتوافق هذه المهارات مع طيعة مقررات المدارس الثانوية التجارية بصفة عامة ومناهج المدارس الثانوية القندقية بصفة خاصة ذات الطبيعة الاكاديمية التطبيقية المماثلة لسوق العمل ،والتي يعد خرجيها للعمل في المجال الفندقي والسياحة التي هي أحد البدائل الهامة لخروج الاقتصاد المصري من أزمته الراهنة ومن بين هذه المقرات مقرر الاقتصاد والذي يتناول موضوعات حيوية وخاصة موضوعات الاقتصاد والسياحة ، والتأثيرات الاقتصادية لصناعة السياحة، والتي تتطلب استخدام طرق تدريس قريبة الى الخبرات المباشرة التطبيقية والأنشطة المعززة بالواقع الافتراضي. أسئلة البحث: - 20 - 20 تحدد السؤال الرئيسي للبحث فيما يلي:

ما فاعلية استخدام استراتيجية ماكفرلاند المدعومة بالواقع الافتراضي في تدريس مادة الاقتصاد على تتمية مهارات اتخاذ القرار، وجوانب الذات الاستثمارية لاى طلاب المدراس الثانوية الفندقية "ج وتفرع من السؤال الرئيسي الأسئلة التالية:

1 - ما مهارات اتخاذ القزار التي يجب تنميتها لاى طلاب المدارس الثانوية الفندقية؟ r - ما جوانب الذات الاستثمارية التي يجب تتميتها لدى طلاب المدارس الثانوية القندقية r - ما التصور لوحدة معاد صياغتها في مادة الاقتصاد لطلاب المدارس الثانوية القندقية باستخدام استراتيجية ماكفرلاند المدعومة بالواقع الافتراضي؟ ـ - ما فاعلية استراتيجية ماكفرلاند المدعومة بالواقع الافتراضي في تدريس مادة

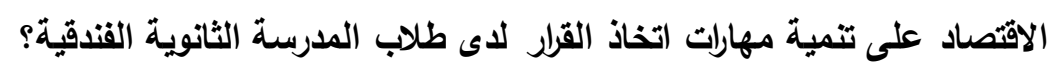


ه - ما فاعلية استراتيجية ماكفرلاند المدعومة بالواقع الافتراضي فى تدريس مادة الاقتصاد على تتمية جواتب الذات الاستثمارية لاى طلاب المدراس الثانوية القندقية الاصن

7- ما العلاقة الارتباطية بين تنمية مهارات اتخاذ القرار وجواتب الذات الاستثمارية

لاى طلاب المدارس الثانوية القندقية؟

$$
\text { فروض البحث: }
$$

تم اختبار فروض البحث بثكل صفري عند مستوى دلاله (0.05) على النحو

- الע يوجد فرق دال احصائيا عند مستوى دلالة (0.05) بين متوسطات درجات

طلاب المجموعتين الضابطة والتجريبية على مقياس مهارات اتخاذ القرار في ملي ملئي

$$
\text { التطبيق القبلي والبعدي. }
$$

r - لا يوجد فرق دال احصائيا عند مستوى دلالة ( 0.05) بين متوسطات طلاب

المجموعتين الضابطة والتجريبية على مقياس جواتب الأت الاستثمارية في

$$
\text { التطبيق القبلي والبعدي. }
$$

r - لا توجد علاقة ارتباطية بين متوسطات درجات طلاب المجموعة التجريبية في التطبيق البعدي بين تنمية مهارات اتخاذ القرار وتتمية جواتب الذات الاستثمارية.

$$
\text { أهداف البحث: - n }
$$

$$
\text { هدف البحث الحالي الى: }
$$

ا - قياس فاعلية وحدة الاقتصاد والسياحة في مادة الاقتصاد المقرة للصف الثالث الثانوي القندقي باستخدام استراتيجية ماكفرلاند المدعومة بالواقع الافتراضي في

تنمية مهارات اتخاذ القرار لدي طلاب المدارس الثانوية القندقية. 
r - قياس فاعلية وحدة الاقتصاد والسياحة في مادة الاقتصاد المقرة للصف الثالث الثانوي القندقي باستخدام استراتيجية ماكفرلاند المدعومة بالواقع الافتراضي في تنمية مهارات الذات الاستثمارية لاي طلاب المدارس الثانوية القندقية.

$$
\text { أهمية البحث: }
$$

قد يساهم البحث الحالي في تظوير بيئة التعلم للتعليم التجاري من خلال:

1 - مسايرة الاهتمام المحلى والعالمي نحو تطوير التّريس واستخذام أساليب

$$
\text { التدريس الحديثة المدعومة بالتكنولوجيا الحديثة. }
$$

r - تقيم نموذج استرشادي لوحدة " الاقتصاد والسياحة " في مادة الاقتصاد المقرة للصف الثالث الثانوي الفتدقي معاد صياغتها باستخدام استراتيجية ماكفرلاند المدعومة بالواقع الافتراضي. r - تقيم دليلاً للمعلم في مادة الاقتصاد للوحدة المختارة باستخدام استراتيجية ماكفرلاند المدعومة بالواقع الافتراضي مما يسهم في الاستفادة منه في العلوم التجارية بصفة عامة، وفى مادة الاقتصاد بصفة خاصة.

ع - المساهمة في تخطيط وعرض مقرر الاقتصاد في المرحلة الثانوية القندقية. ه - تزويد المكتبة التربوية بأدوات بحثية جليدة مثل مقياس مهارات اتخاذ القرار، ومقياس جوانب الذات الاستثمارية.

اقتصر البحث الحالي على الحدود التالية: 1 - اعداد محتوى وحدة "الاقتصاد والسياحة في مادة الاقتصاد للصف الثالث الثانوي باستخدام استراتيجية ماكفرلاند المعززة بالواقع الافتراضي. 
ץ - بعض مهارات اتخاذ القرار (تحديد الأهداف - تنظيم البيانات - تحليل البيانات -

تنمية البدائل - تقويم البدائل - اختيار البليل المناسب - متابعه اتخاذ القرار)

r - بعض جواتب الذات الاستثمارية الجانب (الاقتصادي - الاجتماعي - الإداري).

ع - طلاب الصف الثالث الثانوي الفندقي بإدارة غرب طنطا التعليمية.

\section{مصطاح البحث:}

\section{McFarland Strategy استراتيجية مكفرلاند}

عرفتها ماكفرلاند (McFarland,1985). بأنها " استراتيجية تعليم هادف تؤدي

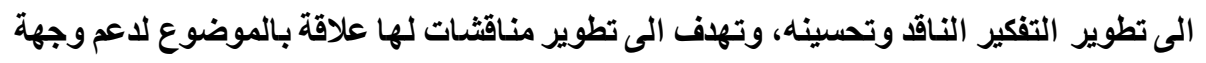

في حين عرفها سعادة (2006) بأنها:" استراتيجية تدريس وتعليم التفكير الناقد

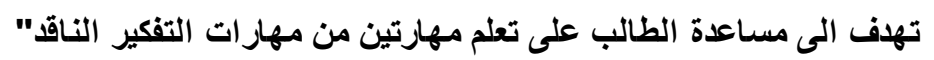

وتُعرف اجرائياً بأنها استراتيجية تدريسية تسير وفق خطوات منطقية متسلسلة

تبلأ بإتاحة الفرصة للطلاب للتعرف على موضوعات وحدة الاقتصاد والسياحة، وطرح وجهات نظر متعدة حول كل موضوع من موضوعات الوحدة وتحليد وجهة النظر الاكثر منطقية والمدعومة بالحجج والبراهين والأدلة التي تثبت صحتها بهدف الوصول الى هون مناقشات المتعلقة بالموضوع محل الدراسة.

$$
\text { الواقع الأتراضي: }
$$

يرى ابراهيم (2015). ان الواقع الافتراضي يشير إلى تمثيل حاسوبي يعمل على

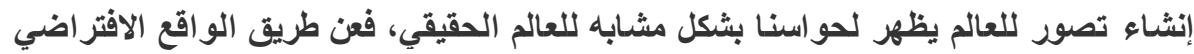
يمكن نقل المعلومات والخبرات إلى الأذهان بشكل جذاب و أكثر تفاعلية.

ويُعرف البحث الحالي الواقع الافتراضي اجرائيا بأنه بناء بيئة افتراضية تسمح

للطلاب بالمشاركة التفاعلية من خلال الوسائط المتعدة المتكاملة عبر شبكات الاتترنت.

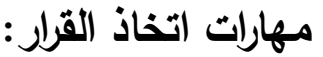


يشار اليه في اللغة العريية على انه توضيح وتحقيق للمسألة او الرأي. (مجمع

اللغة العربية ،2009).

في حين أثشار اليه Chetle (2007) بانه اختيار بليل معين من بين عده

بدائل مطروحة لمجموعه من التحليلات والتفسيرات.

ويعرفه البحث الحالي اجرائياً بانه القدرة العقلية على اختيار أفضل البائل

المطروحة مع مراعاة أهية هذا البيل، والاحتمالية القائمة بإمكان حدوثه في المستقبل.

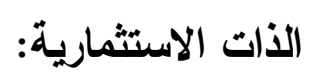

اشنار .Colin,W.I.\& etc.(2008) علي أنها القدرة على توجيه امكانيات

وجواتب النمو المختلفة في المجتمع بتضافر كافة الجهود الوطنية والثعبية لتحقيق

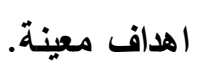

كما أكد فاني Vany (2017) على أنها القرة على الفهم المنظومي لجواتب

الحياة الاستثمارية المختلفة في كافة القطاعات لتحقيق أهاف الرفاهية والاستقرال في الني

المجتمع.

ومن ثم يرى البحث الحالي أن الذات الاستثمارية تمثل القدرة على الفهم

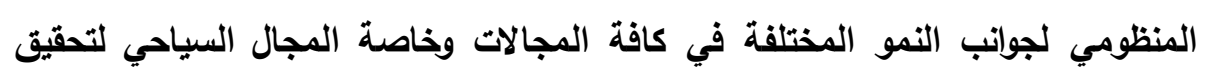

رفاهية وازد هار المجتمع.

الإطار النظري للبحث:

تم تنظيم الإطار المرجعي للبحث في محورين المحور الأول خاص باستراتيجية

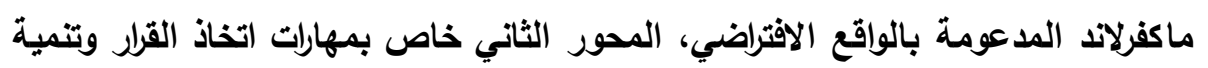

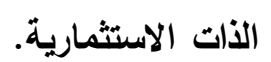

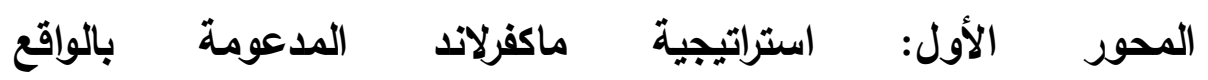

McFarland's Strategy Supported by Virtual الافتراضي

:Reality 
لما كان العصر الذى نعيشه، ونحيا بين جنباته يسمى عصر الوسائط المتعددة، والسموات المفتوحة، التي أزالت كل الحدود ورسمت ملامح عالم جليد قائم على الواقع الافتراضي، وتطبيقاته، من هنا أصبح استخدامه في التعليم بصفة عامة، وفى تدريس العلوم التجارية بصفة خاصة أمراً ضرورياً ، والواقع الافتراضي وتطبيقاته المتعددة يستخدم في عرض ونقل وتحليل البيانات والمعلومات ، فتكنولوجيا الواقع الافتراضي (VR) يمكن أن تساعد الأثخاص على استدعاء المعلومات بشكل أفضل ، مما يجعل البيئة التعليمية أكثر تفاعلية حيث اكلت دراسة (Varshney \& etc,2018) ان الطلاب يتذكرون المعلومات بشكل افضل إذا تم تقليمها لهم في بيئة افتراضية، حيث ان هذه البيئات الافتراضية يمكن أن تقدم مسارات جليدة في التعليم والتدريب عالي الكفاءة مما يجعل العملية التعليمية اكثر متعه وتثويقاً.

وعلى ذلك فان استخام استراتيجية ماكفرلاند المدعومة الواقع الافتراضي في تدريس مادة الاقتصاد يعد من استراتيجيات التدريس القية بوسائل الجذب والاثارة حيث يتحول الطالب من مجرد مستقبل للمعرفة الجاهزة إلى مشارك إيجابي في صناعة المعرفة ، وهذا ما اشارت اليه العديد من البحوث والدراسات السابقة التي أكلت فاعليه استخدام تطبيقات الواقع الافتراضي في التدريس منها دلاسة ميريت (2006 , Merret) التي أكلت ان التدريس المدعوم بمؤثرات الصوت والصورة والحركة والرسوم والاشكال البيانية ترتفع فيه الجودة وامكانية التفكير في مستويات أعلى إلى أكثر من • \& \% وتعد مادة الاقتصاد الفندقي من المواد الدراسية الهامة في مراحل التعليم الفني غير انها لا تلقى الاهتمام الكافي بسبب تركيز الطلاب على المواد الخاصة بالجوانب التطبيقية بعيداً عن السرد النظري لهذا كاتت الطرق التقليدية في التريس لهذه المادة غير مناسبة لتتمية المهارات العليا من التفكير(Gisho,2011). ومن هنا أصبح استخدام استراتيجيات تدريس حليثة تعتمد على تطبيقات الواقع الافتراضي في تدريس مادة الاقتصاد القندقي لاى طلاب المدارس الثانوية القندقية يلعب 
دواً مؤثراً في تنمية مهارات التفكير العليا، والاتصال والمشاركة، والفاعلية في المواقق المختلفة. (Kelten,2009)

ولتطبيقات الواقع الافتراضي في التريس العليد من المداخل التي تضيف غناصر التشويق والاثارة على العملية التعليمية مما دفع بالتربويين إلى استخدامها في مجال التتريس كما انها ذات جدوى للمعلم في تفاعله مع مستجدات العصر ويالتالي ينتقل

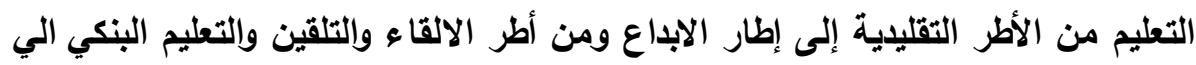

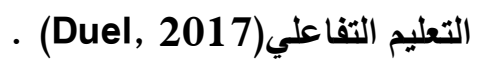

\section{: McFarland Strategy : استراتيجية ماكفرلاند}

تعد هذه الاستراتيجية من الاستراتيجيات المهمة في تعليم التفكير الناقد وتتسب الى المربية ماري ماكفرلاند (Mary Mcfarland) وكانت تهذف من ورائها الى تقديم أمثلة تساعد على تعليم مها رات التمييز بين المعلومات ذات الصلة بالموضوع والمعلومات التي لا ترتبط بالموضوع، كما توضح العديد من اتجاهات التفكير الناقد التي من الممكن أن تظهر من وقت لآخر. (القمش والجوالدة ،2016).

بينما تثير اليها جمعية الحقوق التريوية بولاية اوهايو(E.A.G.,2011) بأنها أحد استراتيجيات تعليم التفكير حيث تعتمد على نوعين من الاجراءات الاول في الكلمات المترايطة، وإثاني في الافاع عن وجهات النظر، ويالتالي فان استراتيجية ماكفرلاند تهتم بتعليم مبادئ التفكير، والقدرة على اتخاذ القلار، وامكانية الاتصال والتفاعل وذلك من خلال عرض كلمات عديدة حول موضوع واحد مع وجود كلمه بعيدة عن الموضوع نهائياً، وإتخاذ كافة الإجراءات من أجل الوصول إلى عملية عقلية لترتيب الكلمات واظهار وجهات النظر

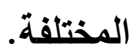

ومن ثم فان استراتيجية ماكفرلاند تقوم بمعالجة المعلومات التي تؤكد مهارات التفكير العليا مثل الفهم، والتحليل اختيار البدائل، والمشاركة، والتواصل ويالتالي امكانية اتخاذ القرار، ويذلك تحقق استراتيجية ماكفرلاند نوعاً من حرية التفكير، وامكانية التمرد 
على الثكل التقليدي للمعرفة الجاهزة القائمة على مقتضيات التعلم البنكي "(تعليم المقهورين) ، والانطلاق إلى شكل مغاير من النقد والتحليل واختيار البائل، والقدرة على (تخاذ القزار، والمشاركة والتواصل وغيرها.(Wentte,2012) خطوات استراتيجية ماكفرلاند: تتعدد خطوات استراتيجية ماكفرلاند في:(George,2015) 1 - عرض مجموعة من الكلمات ما بين (0 - V ) كلمات كلها مرتبطة بموضوع معين في مادة معينة، ما عدا كلمة واحدة تكون غير مرتبطة نهائياً بالموضوع. r - تحدد الاربع كلمات او الست كلمات المرتبطة بالموضوع بعد مناقثات جماعية مع الطلاب، وشطب الكلمة الوحيدة الغير مرتبطة. r- بطلب المعلم من الطلاب ما يالي: - تركيب الكلمات الستة أو الاربعة المرتبطة بالموضوع في جملة مفيدة او موقف حياتي. - ترابط الكلمات بشكل منطقي ومنظم. - تقيم وجهة نظر منطقية عقب كل موضوع. ع - تقويم ما قدمه الطلاب حيث يقوم المعلم بالكشف عن مدى اسهام الطلاب في الكثف عن الخطأ المتمثل في الكلمة المختلفة، وقدرتهم على ترتيب الكلمات وتركيبها في جملة أو موقف معين مرتبط بالموضوع، ومناقشة الطلاب في وجهات نظرهم المختلفة. ويرجع اختيار استراتيجية ماكفرلاند لتدريس مادة الاقتصاد القندقي لطلاب المدارس الثانوية القنية القندقية للاعتبارات الأتية: 1 - الصلة الوثيقة بين استراتيجيات تعليم التفكير وتتمية مهارات التفكير حيث ان استراتيجية ماكفرلاند واحدة من استراتيجيات تعليم التفكير. 
r - تتمية مهارات اتخاذ القرار، وتنمية جواتب الذات الاستثمارية يرتبط ارتباطاً وثيقا باستراتيجيات التدريس التي تهتم بالمتعلم وإنشطته. r - مناسبة هذه الاستراتيجية وملائمتها لمستوى النمو العقلي لطلاب المدارس الثانوية الفنية القندقية. ؟ - ما اشارت اليه بعض نتائج البحوث والدراسات السابقة من جدوى هذه

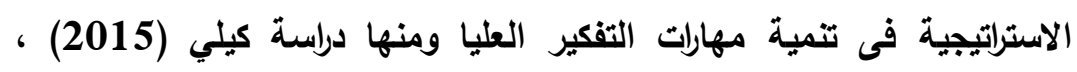
ودراسة العرنوسي وهاشم (2016) ، ودراسة الحوري ، وآخرون (2009). ه- الارتباط الوثيق بين اهداف تدريس مادة الاقتصاد الفندقي ويين أهداف استراتيجية ماكفرلاند المدعومة بتطبيقات الواقع الافتراضي التي تسعى إلى تتمية مهارات التفكير العليا. צ - التعود على العمل الجماعي، وروح الفريق من خلال المناقشات الجماعية. V- التوافق مع روئية مصر للتعليم العام، والقني (2030) في تتمية جوانب الشخصية المختلفة، والاهتمام بجوانب الابداع والتفكير. 1 - قله البحوث والدراسات السابقة في مجال تدريس الاقتصاد الفندقي التي اهتمت باستراتيجيات تعليم التفكير، ومنها استراتيجية ماكفرلاند على حد علم الباحثة. الواقع الافتراضي: يُشير الواقع الافتراضي إلى انثاء بيئة تصورية للعالم مشابهة للحقيقة بواسطة استخدام الحاسب الآلي وتطبيقاته المرتبطة وخاصه الانترنت تظهر لحواسنا بشكل مشابه للعالم الحقيقي، فعن طريق الواقع الافتراضي يمكن نقل المعلومات والخبرات إلى الأذهان بثكل جذاب وأكثر تفاعلية فيه تجسيد مبسط للواقع لكنه ليس حقيقياً حيث يعطينا امكانيات لا نهائية للضوء، والامتداد، والصوت والاحساس والروئيا وإضطراب المشاعر كما لو أنها في الواقع الفيزيائي الطبيعي. وذلك باستخدام الزمن الحقيقي Real Time وليس ولايس فقط جعل المستخدم مراقباً خارجياً لها. (نابلسي، 2016). 
ويرجع تاريخ تقتية الواقع الافتراضي الى المفكر الأمريكي آرثر كلارك فهو من

أوائل من حلم بالواقع الافتراضي وأصدر كتابا عن الخيال العلمي أسماه الواقع والنجوم ، وقد تخيل في عرضه للكتاب منذ نصف قرن من الزمان إلى وجود مدينة مستقبلية يقوم أفرادها بالاتصال فيما بينهم من خلال الاجتماعات والمؤتمرات بواسطة أجهزة إلكترونية متقدمة يتشاورون ويناقشون كثيرا من القضايا المهمة عبر هذه الأجهزة الإكترونية التي لا تتطلب حضورهم إلى تلك المواقع على الرغم من تباعد أماكنهم بمسافات طويلة ولكن التطبيق الفعلي لهذه التقية بدأ في أواخر الستينات من القرن العشرين ، حيث بدأ مايرون كروجر Myron Krueger الملقب بأبي الواقعية الافتراضية) في اختراع بيئات افتراضية يتحرك فيها المعلم تحت شعار "تعال كما أنت "comes as you are ، كما بنى كروجر بيئة افتراضية جديدة أسماها الفضاء النفسي Psychic Space تسمح للمشاركين بالمشاركة التفاعلية من خلال صور فيديو حيه يمكن تحريكها وإدارتها دون الأخذ في الاعتبار القوانين التقليلية للسبب والنتيجة.(Davis,2015 ) وفى البيئة العربية بصفة عامة، والمصرية بصفة خاصة استخدم مصطلح الواقع الافتراضي لأول مرة عام 1989 تحت مسمى الواقع الخائلي او الوهمي وهو أكثر اتساقاً مع اللغة العربية لقابليته للاشتقاق ويمكن النظر إلى الخائلية على أنها بيئة اصطناعية لممارسة الخبرات بصورة أقرب ما تكون إلى الصورة الموجودة في دنيا الواقع. (نبيل ،

ينقسم الواقع الافتراضي المستخدم في عملية التعليم إلى عدة انواع منها:( شريفي

1 - الفصول الافتراضية المتزامنة: وهي عبارة عن مدرسة افتراضية عبر شبكه

الاتترنت يشترك فيها المتعلمون من بلان العالم المختلفة في التوقيت يربط 
بينهم اهتمام أكاديمي مشترك أوصف دراسي واحد ويينهم اتفاق على أسلوب التريس، والحوار والمناقثة مع باقي الاعضاء.

r - الفصول الافتراضية الغير متزامنة: وهي عبارة عن مدرسة افتراضية عبر شبكة الاتترنت يشترك فيها المتطمون من بلان مختلفة وفى أوقات مختلفة، وهذا النوع يقوم بنشر وتخزين المقررات والمحاضرات التعليمية ووسائل الثرح

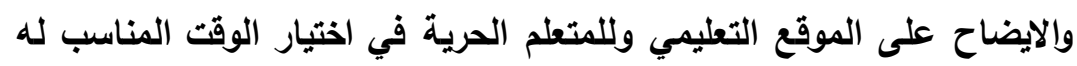

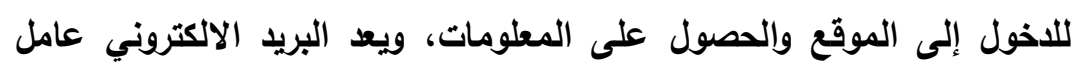

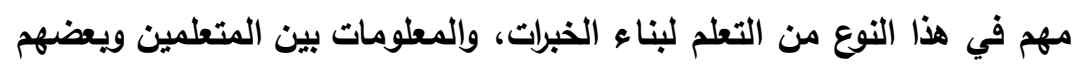

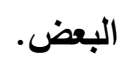

أهمية الواقع الافتراضي في التطيم : تكمن أهمية الواقع الاقتراضي في أنه يمثل الواقع الحقيقي، فهو يعتبر وسيلة

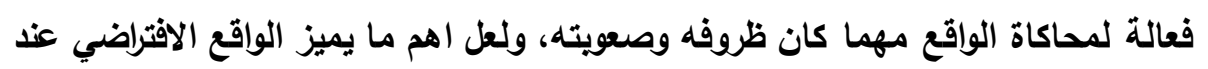
تطبيقه في مجال التعليم ويجعله وسيلة ممتازة من وسائل التعلم عدا من الأمور أهمها: (رياض،2016)

1- الانغماس: وهو الثعور الذي يتولد لاى مستخدم برامج الواقع الافتراضي بأنه

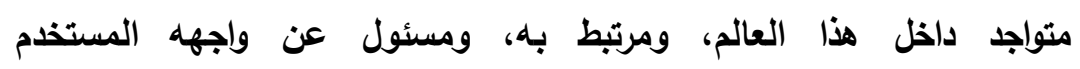
الرسومية Graphic user interface حيث يوفر الواقع الافتراضي فضاء ونهاء

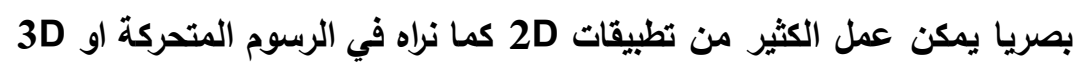

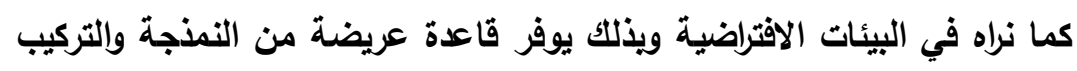
والاضاءة والرسوم المتحركة والتي تحاكي الواقع الفعلي.

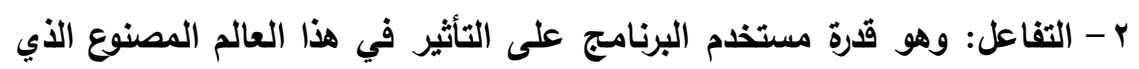
يراه أمامه، والتعامل معه بنفس المنطق الأي يستطيع التعامل به ميع الحياة العادية، فلا يكون ملزماً بسلوك بعينه، أو زوايا رؤية لا يحيد غنها.

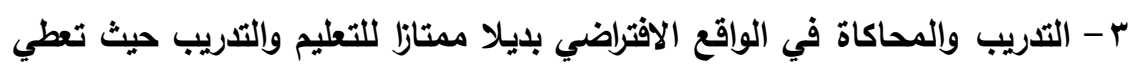
فرصا للطالب بالتكرار والتعطم بالمحاولة والخطأ، والمحافظة على التكلفة المادية. 
ع - إمكانية تلافي الأخطار المتوقعة في العالم الدقيقي، حيث يسمح الواقع الافتراضي بارتكاب اخطاء لا بترتب عليها خسائر مثل دراسة المفاعل النووي أو قيادة الطائرة وغيرها. ه- تسمح للطلاب بإجراء التجارب المعلية خطوة بخطوة كما تهيئ له فرصة الاستمرار في التجرية خلال مدة زمنية مفتوحة وياستخلام تقبيات جديدة عبر الاستعمال الفعلي للتجرية، وتهيئ الطالب للتفاعل مع التجربة الافتراضية والمشاركة الايجابية فيها وفق النتائج التي يحصل عليها. \ - تشجع الإبداع والابتكار عند الطلاب في البرامج التي تعتمد على الإنشاء والخلق والتصنيع. V- تشجيع الطلاب على تجاوز حالة التلقي السلبي للمعلومات لينطقوا نحو المشاركة الفعالة في التعليم والتي تؤكد مبأ التعليم الذاتي.

سلبيات الواقع الافتراضي في التعليم: (أحمد، عبد الحميد، 2012 ) على الرغم من فاعلية الواقع الافتراضي وأهميته في مجال التعليم والتدريب، إلا أنه لا يخلو من السلبيات التي تعيق من عملية استخدامه ومن هذه العيوب والسلبيات: 1 - محدودية استخدام الواقع الافتراضي في مدارس التعليم المختلفة نتيجة ارتفاع تكاليف الاجهزة، وارتفاع تكاليف انتاج البرمجيات. ץ - محدودية تأثير الحواس الخمس في نظام الواقع الافتراضي الأي لا يتجاوز في استخدامه إلا حاسة السمع والبصر واللمس، ولكن ريما ستظهز مستجدات أخرى تستخدم باقي الحواس الأخرى في المستقبل. r - الاستخدام المفرط لتطبيقات الواقع الافتراضي في التعليم له تأثثراته السلبية حيث ينشغل المتعلم عن الموضوع الحقيقي، وينصرف إلى مؤثرات الصوت والصورة والحركة. ؛ - الجلوس لفترات طويلة امام الواقع الافتراضي يصيب الجسم بالإرهاق واللاعياء لله تأثيره السلبي على الأجهزة العصبية. 
ه-الانغماس في الواقع الافتراضي يؤدي إلى تضاؤل الدور الاجتماعي، وفقد قيمه

التواصل بين الأطراف المختلفة من الناس في المستوى الحقيقي من الحياة. وعلى الرغم من وجود بعض السلبيات لاستخدام الواقع الافتراضي في

التعليم الا ان إيجابياته في عملية التعليم والتدريب فاقت تلك السلبيات، ومن هنا أصبح استخدام الواقع الافتراضي في التريس بصفه عامة، وفي تدريس العلوم التجارية بصفه خاصه امراً ضروريا من اجل تجاوز النمطية إلى الابداع وتجاوز التقليلية إلى التجليد وهذا ما أكلته دراسة عبد العزيز( 2014) حيث اكلت فاعلية البيئة الاكترونية في تتمية مهارات التعامل مع الاجهزة المكتبية ، كما اكلت دراسة فودة (2017)،على الهية استخدام المديولات الرقمية في تتمية المهارات المصرفية لطلاب التعليم الفني، كما أثتبت دراسة سلام(2016) فاعلية بناء الوحدات التعليمية باستخدام المديولات الرقمية في تنمية المعرفة العلمية والقدرة على اتخاذ القرار لاى طلاب المعلمين بالثعب العلمية بكلية التربية جامعة طنطا

وثمة فرق بين الواقع الافتراضي، والواقع المعزز فالواقع المعزز هو نوع من الواقع الاقتراضي الذي يهذف إلى تكرار البيئة الحقيقية في الحاسوب وتعزيزها بمعطيات افتراضية لم تكن جزعا منها. ويعبارة أخرى، فنظام الواقع المعزز يولد عرضا مركبا للمستخدم يمزج بين المشهر الحقيقي الذي ينظر إليه المستخدم والمشهر الظاهري التي تم إنشاؤه بواسطة الحاسوب والذي يعزز المشهر الحقيقي بمعلومات إضافية. يهذف المشه الظاهري virtual scene الذي تم إنشاؤه بواسطة الكمبيوتر إلى تحسين الإدرالك الحسي للعالم الحقيقي الأي يراه أو يتفاعل معه المستخدم. ويهذف الواقع المعزز إلى إنشاء نظام لا يمكن فيه إدراك الفرق بين العالم الحقيقي وما أضيف عليه باستخلام تقتية الواقع المعزز، فعند قيام شخص ما باستخدام هذه التقتية للنظر في البيئة المحيطة به فإن الأجسام في هذه البيئة تكون مزودة بمعلومات تسبح حولها وتتكامل مـع الصورة التي ينظر إليها الشخص. 


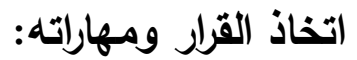

تلعب عمليه اتخاذ القرار دورا هاما في تحديد مستقبل الثعوب والجماعات

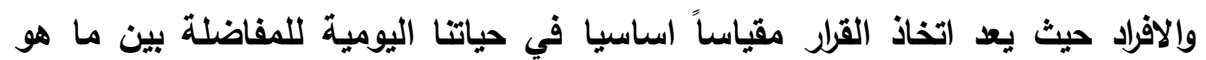
مطروح من اجل الوصول إلى القرال المناسب، حيث أن مهارات اتخاذ أو صنع القرال توفر التران

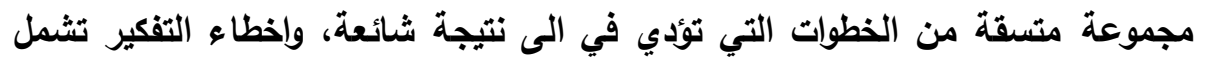
عملية اتخاذ القزار الاختيار بين الحلول الممكنة للمشكلة. يمكن اتخاذ القرارات من خلال

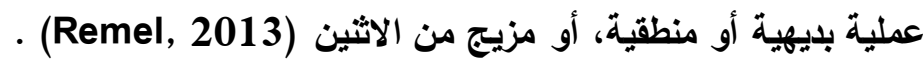
مهارات اتخاذ القزار، والطريقة العلمية للتوافق عليها: اتخاذ القزار بشأن موضوع معين يغني الالتزام بسلوك معين ومحدد من أجل

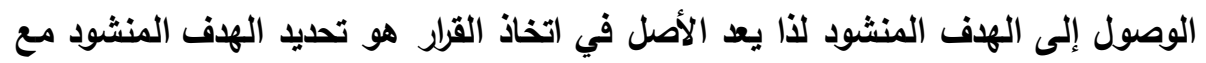

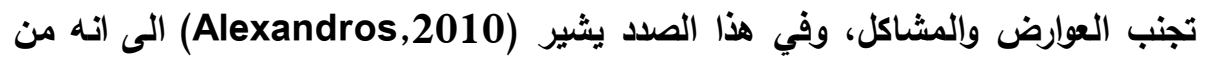
خلال الاستراتيجيات التعليمية واستخام التكنولوجيا التعليمية يمكن تحسين استراتيجيات اتخاذ القرال لاى طلاب الددارس وطلاب الجامعة

واتخاذ القرار يتم وفق طرق وانماط لتماط مختلفة منها:

1 - اسلوب التجربة والخطأ: يتم اتخاذ القراد وفقا لهذا الأسلوب، عن طريق التجرية الثخصية لصانع القرار، ومثاهته لقرارات تم اتخاذها في مثل هذه المواقف، استنادا علي قررة الفرد نفسه متخذ القرار، وروئته للمواقق المختلفة، وتحليل كتلك المواقف. ويغي اعادة نفس السلوك والمواقف مرات عديدة من أجل التطلم من الاخطاء والوصول إلى قرار مناسب. (Fredirck, 2014) ץ- اسلوب التقليد والمحاكاة: وفقا لهذا الاسلوب يتم اتخاذ القرار بناءُ على تقليد نماذج وقلات فكرية معروفة ولها رؤية منهجية محددة من أجل الوصول إلى لنى

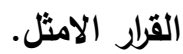
ץ- اسلوب الخبرة السابقة: يعتمد اتخاذ القزال وفقا لهذا الاسلوب على استدعاء المواقت والخبرات المثابهة لمواقت حياتيه ممثله في حياتتا الحالية من اجل هلئل

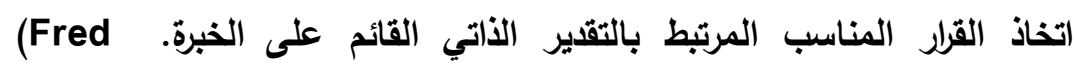


؛ - الاسلوب العلمي في اتخاذ القرار: يعتمد هذه الاسلوب على اتخاذ القرار في ضوء

خطوات المنهج العلمي في التفكير حيث يعد " ديوى " اول من استخدمها، وتعتمد على ثلاثة تساؤلات ممثلة في: ما المشكلة؟وما البدائل المتاحة لحالها؟؛

وأي هذه البدائل أفضل؟

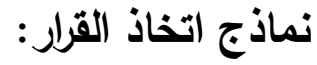

من خلال الاطلاع على بعض البحوث والدراسات السابقة ويعض الاطر المرجعية التي تتاولت نماذج اتخاذ القرار منها: الشوادفي (2016)، سلام (2016)، Fredric (2014), Alexandros (2010)

1-نموذج ريو وياير: وتتمثل خطوات اتخاذ القرار وفقا لهذا النموذج في (الحاجة الى اتخاذ القرار -ترتيب الحاجات-جمع المعلومات تتعريف البدائلتقويم كل بديل - اختيار البليل المناسب) r - نموذج فالتش ودريدرج: تتمثل خطوات هذا النموذج في (تحليد التناقض في الوضع القائم تتحديد عناصر اتخاذ القرار -التخل الشخصي لمعرفة اسباب التناقض -التفضيل بين البدائل †التطبيق †التقويم) r- نموذج كارين: تعتمد خطوات هذا النموذج على (التخطيط ويتم فيها تحليد المشكلة-تحليد البيانات -تظيم البيانات -تحليل البيانات -تركيب البيانات -تخاذ

وفي ظل العرض السابق يمكن أن نشير إلى أن عملية اتخاذ القرار عملية مركبة تمر بعدة مراحل تتذاخل فيما بينها، وتحتاج إلى العديد من المهارات العقلية للوصول إلى القزار المناسب والصحيح بقر الامكان، ويالتالي يمكن تحلد خطوات ومراحل ومهارات اتخاذ القرار في الجواتب التالية وفق روية البحث الحالي: 1 - تحديد الاهداف: حيث يحلد متخذ القرار الهدف المراد الوصول اليه من وراء اتخاذ القرار لهذا يصبح في حاجه الي معلومات وييانات ومعطيات. r - تنظيم البيانات: يتم جمع البيانات المرتبطة بالموضوع في مجال اتخاذ القرار، ويتم تنظيمها بشكل منطقي وعقلي جيد من السهل إلى الصعب، ومن البسيط 
إلى المعقد، ومن المعلوم إلى المجهول بما يتفق ميع التركيب العقلي والبناء المعرفي لمتخذ القرار كما اشار" اوزويل ". r- تحليل البيانات: يتم تحليل وتفسير البيانات التي تم تتظيمها، وتحليد مدى التوافق والارتباط بينها أو أي تتاقض بينها، حتى يصبح هناك القرة على اتخاذ القرار بشكل مناسب ومعقول. ع - تتمية البدائل: وذلك بتحليد الاجراءات التي تتذذ من أجل الوصول الي قرار مناسب، وذلك بابتكار أكبر عدد ممكن من البدائل المقبولة، والمنطقية ه - تقويم البدائل: وذلك من خلال تحليل البدائل المطروحة لمعرفة مزايا وعيوب كل بديل، والمخاطر المرتبطة بكل بديل حتى يمكن اختيار أكثر البدائل ميزات وأقلها عيوب ومخاطر. ד - اختيار البديل المناسب: وذلك بعد تفوق كل بديل من البدائل على غيره مما هو مطروح من تلك البدائل، وهنا تمارس مهارات توقع النتائج والاختيار بين البدائل. V - متابعه اتخاذ القرار: حيث يتم اتخاذ القرار المناسب في ضوء تحليل البدائل المطروحة، ومتابعة كل بليل في سياق منطقي، والقيم المرتبطة به، والكافية

وراء هذا القرار. العوامل المؤثرة في نوع القرار:

يتأثر اتخاذ القزار بعدة عوامل تتمثل في: (أمين ، 2018)، (رضوان، 2012) 1 - الدوافع الانساتية التي تختلف من شخص إلى اخر غير انها تنظم السلوك وتوجهه. r - الخبرات السابقة التي تعطي متخذ القرار مؤشرا بالموافقة أو الرفض، ويالتالي اتخاذ القزار المناسب من وجهة نظره اعتمادا على ما لايه من خبرات. r- فلسفة المجتمع فالإطار القلسفي والفكري للمجتمع، وظروفه السياسية، والاجتماعية، والاقتصادية، وما يمارسه من سياسات تجارية ورأسمالية أو ليبرالية أو شيوعية أو غيرها تكون محداً قوياً لاتخاذ القرار. 
ولما كاتت ثمة علاقه وثيقه أثشارت إليها بعض البحوث والدارسات السابقة بين استراتيجيات التذريس المستخدمة في تدريس مادة الاقتصاد وبين القدرة على اتخاذ القرار ومنها دراسة (2017) Even(2017 ودراسة ، ودراسة سلام (2016) Alexandros.(2010) , Fredric(2014) ودراسة، والتي أكلت علي دور استراتيجيات تعليم التفكير في مساعده الطلاب على اتخاذ القرار المناسب لهذا جاء اهتمام البحث الحالي بدراسة دور استراتيجية ماكفرلاند كأحدي استراتيجيات تعليم التفكير في تتمية مهارات اتخاذ القرار.

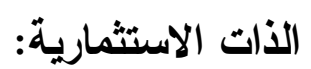

لما كنا في عالمنا المعاصر قـ أطلق شعار صناعه الذات، وتتمية الذات وخاصة في الجوانب الاستثمارية المتعدة والمختلفة، ولما كان الاستثمار السياحي هو أحل جوانب الاستثمار الأكثر أهمية في وقتنا الحالي في ظل ما يسمى بتثشيط حركة الاستثمار واعادة هيكلة الاقتصاد العالمي فان الاهتمام بتتمية جوانب الذات الاستثمارية أصبح أمراً لا غنى غنه ويخاصة لاول العالم النامي وهذا ما اشارت اليه العديد من الأببيات والمرجعيات مثل:

Del Boca \& etc. (2012), Rosel (2014). مفهوم الاستثمار : - م يعرفه (Del Boca \& etc. بأنه صناعة ذات اوجه متعددة ومتداخلة تتخذ من الشراكة الفعالة التي تضم مؤسسات المجتمع المدني بقطاعيه العام، والخاص، الافراد، والجماعات محورا أساسياً من أجل تحقيق أهداف محدده لخدمه المجتمع والترويج لتجارته وأنماطه المختلفة التي من بينها السياحة.

فلقد أدت العولمة إلى انفتاح الأسواق وزيادة حجم التبادلات وإنتقال رؤوس الاموال عبر القارات حتى أصبح العالم كله قرية صغيرة الأمر الذي أدى إلى تتامي الاستثمار في قطاعات عليدة ومن بينها الاستثمار السياحي. الأات الاستثمارية: 
اشار والت Wallet (2017) علب أنها القدرة على توجيه امكانيات وجواتب

النمو المختلفة في المجتمع بتضافر كافة الجهود الوطنية والشعبية لتحقيق اهداف معينة. كما يؤكد فاني Vany (2017) على أنها القدرة على الفهم المنظومي لجوانب الحياة الاستثمارية المختلفة في كافة القطاعات لتحقيق أهداف الرفاهية والاستقرار في

يشير خالد (2014 ) إلى جوانب الأت الاستثمارية في النقاط التالية:

اولا: حسب النوع: وتصنف الي:

- - الجاتب الاقتصادي ممثلاً في الخدمات والسلع المخصصة للاستثمار. - - الجاتب الاجتماعي ممثلا في رفاهية الافراد والجماعات. - - الجانب الاداري ممثلا في تطوير الاماكن والمؤسسات التي تهتم بالحفاظ على المجتمع. ثانيا: حسب الادوات: وتصنف إلى:

- الاستثمار الحقيقي: ويعرف ايضا باسم استثمار الأعمال أو المشروعات، ويوفر للمستثمر الحقوق في الحصول على أصول

$$
\text { حقيقية مثل الذهب والعقارات. }
$$

- الاستثمار المالي: ويمثل جانبا من جوانب الذات الاستثمارية في الحصول على حصة من رأس المال او قرض يوفر أرباح مضمونة وفقا للقانون. - الاستثمار المعنوي: وهي تتمثل في الاستثمار المعتمد على حصول الأفراد والمؤسسات على بعض المعرفة أو الأصول الفكرية مثل تنفيذ بحث علمي من خلال باحث أكاديمي او من خلال مؤسسة تعليمية او

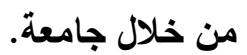
ثالثاً: حسب معيار التعدد وعدمه: وتصنف إلى: 
- الاستثمار المتعدد ويعرف باسم استثمار المحفظة، وهو الاستثمار في

أكثر من نوع من انواع الادوات الاستثمارية المالية او المادية.

- الاستثمار الغير متعدد: وهو المشاركة باستثمار واحد مثل شراء أصل الصن

$$
\begin{aligned}
& \text { مادي هو مادي واحد فقط } \\
& \text { رابعا: وفقا لمعيار الملكية: وتصنف إلى: }
\end{aligned}
$$

- الاستثمار الخاص: وهو استثمار ينفذه فرد او مجموعة من الافراد

$$
\text { بشكل قانوني ضمن شركة خاصة }
$$

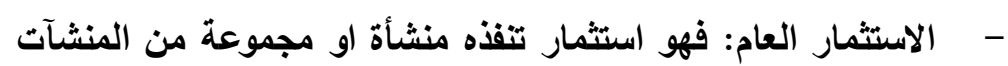

$$
\text { تتبع ملكيتها للاولة ضمن شركة عامة }
$$

- الاستثمار المختلط: وهو استثمار يجمع بين العام وإلخاص يشارك فيه

الافراد والجماعات والمؤسسات الخاصة والعامة.

ولقد تبني البحث الحالي جوانب الأت الاستثمارية التالية:

$$
\text { - - - - الجاتب الاقتصادي - - الجاتب الاجتماعي لاداري }
$$

1 - لكونها تتفق مع اهداف تدريس مادة الاقتصاد في المدارس الثانوية الفنية. r - تتوافق مع روئة مصر (2030) والتي تسعى إلى تتمية جوانب الاستثمار المختلفة.

r - الاهتمام بتتمية الجواتب الاقتصادية والاجتماعية والإدارية مطالب ضرورية لحياة

$$
\text { القرن الواحد والعشرين. }
$$

ع - الاهتمام بقطاع السياحة باعتبارها أحد أهم الجوانب الاقتصادية فضلا عن تداخله

$$
\begin{aligned}
& \text { مع الجوانب الاخرى. } \\
& \text { المنهجية والاجراءات: }
\end{aligned}
$$




\section{منهج البحث

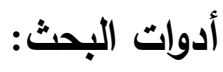

1 - دليل المعلم باستخام استراتيجية مكفرلاند المدعومة بالواقع الافتراضي لتكريس بعض موضوعات مادة الاقتصاد المقرة على طلاب الصف الثالث بالمدارس الثاني الثانوية القندقية (من اعداد الباحثة)

r - قائمة بأهم مهارات اتخاذ القرال (من اعداد الباحثة) ب- ب - مقياس مهارات اتخاذ القراد (من اعداد الباحثة) ع - قائمة بأهم جوانب الأات الاستثمارية (من اعداد الباد الباحثة) ه - مقياس جواتب الذات الاستثمارية (من اعاد الباحثة).

اعتمد البحث الحالي على استخدام المنهج الوصفي والمنهج شبة التجريب 1 - المنهج الوصفي في جمع وتفسير البيانات، ووصف أداء الطلاب على مقياس

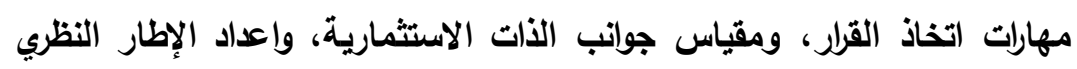
للبحث، ومناقثة وتفسير النتائج.

r- المنهج شبة التجريبي: في ضوء طيعة البحث الحالي والهلفف منه، وطييعة متغيراته اعتمد البحث المنهج شبه التجريبي، لضبط واستبعاد بعض المتنغيرات

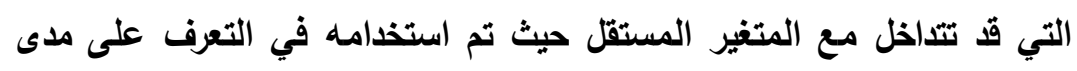

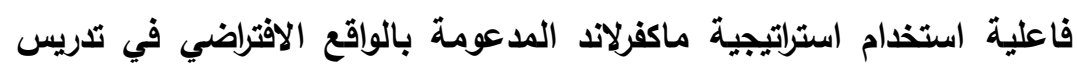

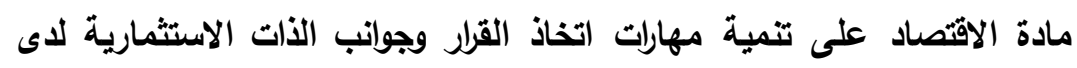
طلاب المرحلة الثانوية القندقية من خلال تطبيق أدوات البحث (مقياس مهارات اتخاذ القزار، ومقياس جوانب الذات الاستثمارية). 
يتمثل مجتمع البحث الحالي في طلاب الصف الثالث الثانوي الفتدقي بإدارة غرب طنطا التعليمية للعام الدراسي 2018-2019 الفصل الداسي الأبئ الأول.

عينة البحث:

تمثلت عينة البحث في مجموعة من طلاب الصف الثالث الثانوي القندقي بمدرسة طنطا الثانوية الفندقية المشتركة، والتي بلغ عددها ( • ؟) طالباً تم اختيارهم بطريقة عشوائية وتقبيمهم إلى مجموعتين أحدها ضابطة يتم التدريس لها باستخدام الطريقة التقليدية،

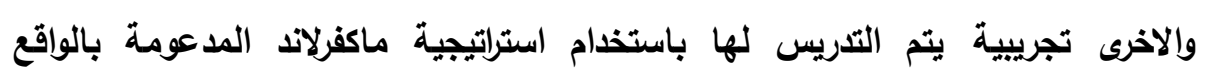
الافتراضي، ويلغ عدد كل مجموعة (• (r) طالباً.

$$
\text { التصميم التجريبي للبحث: }
$$

في ضوء طبيعة البحث ومتغيراته المستقلة والتابعة، وفي ضوء طريقة اختيار عينة البحث وتوزيعها على المجموعات، تم اعتماد التصميم التجريبي للبحث على المجموعة الضابطة مع القياس القبلي والبعدي للمتغيرات التابعة والجدول التالي يوضح طريقة التصميم التجريبي للبحث.

$$
\text { جلتول التصميم التجريبي للبحث }
$$

\begin{tabular}{|l|l|l|l|}
\hline المجموعات القياس القبلي & & \\
\hline
\end{tabular}




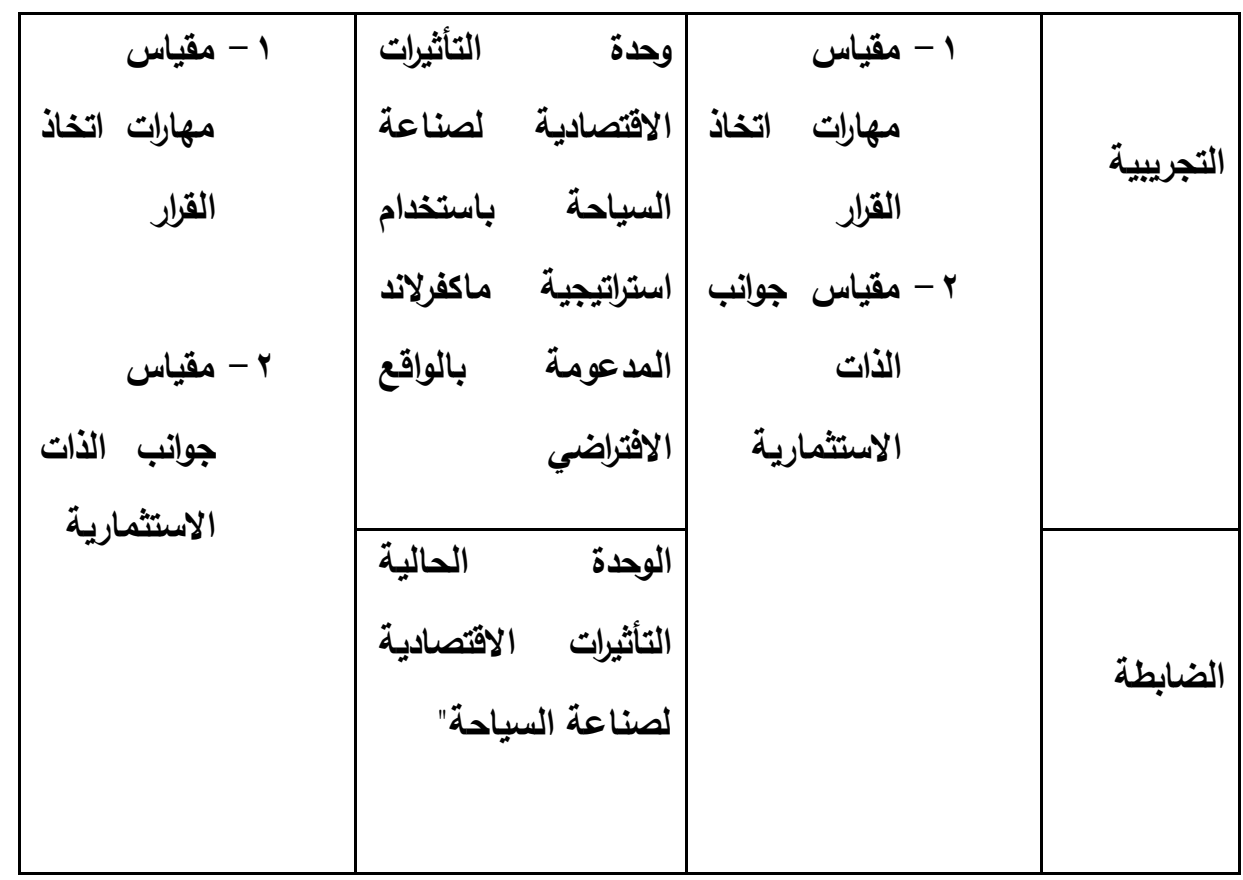

أدوات البحث:

تتمثل أدوات البحث فيما يلي

- مقياس مهارات اتخاذ القرار (من اعداد الباحثة).

- مقياس جوانب الذات الاستثمارية (من اعداد الباحثة).

اولاً: اعداد مقياس مهارات اتخاذ القرار :

تم اعداد مقياس مهارات اتخاذ القرار وفقا للخطوات التالية:

الهدف من المقياس: قياس مدى توافر مهارات اتخاذ القرار لاي طلاب

المدارس الثانوية الفتية. 
أبعاد المقياس: تم تحديد أبعاد المقياس في ضوء:

- - الأطر النظرية المرتبطة باتخاذ القزال.

- - البحوث والدراسات السابقة في مجال اتخاذ القرار.

- بض مقاييس اتخاذ القزال التي اطلت عليها الباحثة.

وفي ضوء ما سبق تم تحديد مهارات اتخاذ القرال في سبعة مهارات أساسية هي:

1 - مهارة تحديد الأهداف: يقصد بها التحديد الواضح والدقيق للهذف المراد تحقيقه

من اتخاذ القرار وذلك في ضوء المططيات والبيانات الكافية عن الظروف السائدة

$$
\text { واحتمالات النجاح. }
$$

ץ - مهارة تنظيم البيانات: وتغني ترتيب البيانات والمططيات في شكل منطقي ومنظم من السهل إلى الصب ومن البسيط للمعقد.

r- مهارة تحليل الييانات: وتثير الى تفني وتفسير البيانات التي تم تتظيمها وتحليد مدي التوافق والارتباط، والتتاقض بينها حتى يمكن اتخاذ قرار مناسب.

ع - مهارة تنمية البائل: وتتمثل فيما يتم اتخاذه من إجراءات من أجل ابتكار أكبر

$$
\text { عدد ممكن من البدائل المنطقية. }
$$

ه - مهارة تقويم البائل: وتثير الى تحليل البدائل لتحليد المنفعة والقيمة المستقبلية

للبديل، ومن ثم تحليد الأهمية النسبية للبديل بالنسبة للبدائل الأخرى.

צ- مهارة اختيار البديل المناسب: وفيها يتم المفاضلة بين البائل المختلفة لمعرفة

مدي تفوق وتميز كل بديل عن البدائل الأخرى من حيث نقاط القوة، والضعف. 
V - مهارة متابعة اتخاذ القرار: وتعني اتخاذ القرار في ضوء التتابع المنطقي للبائل وما يترتب على القزار من نتائج وما يصادفه من صعويات، وإمكانية تطوير هذا القرار صياغة مفردات المقياس:

تم إعداد المقياس في صورته المبائية من قبل الباحثة معتمدة على آراء الخبراء والمتخصصين، الخبرة الأكاديمية والتريوية للباحثة، البحوث واللاراسات السابقة، الأطر النظرية والمرجعية في مجال إعداد المقاييس، وقد تم مراعاة المعايير التالية في صياغة

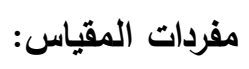

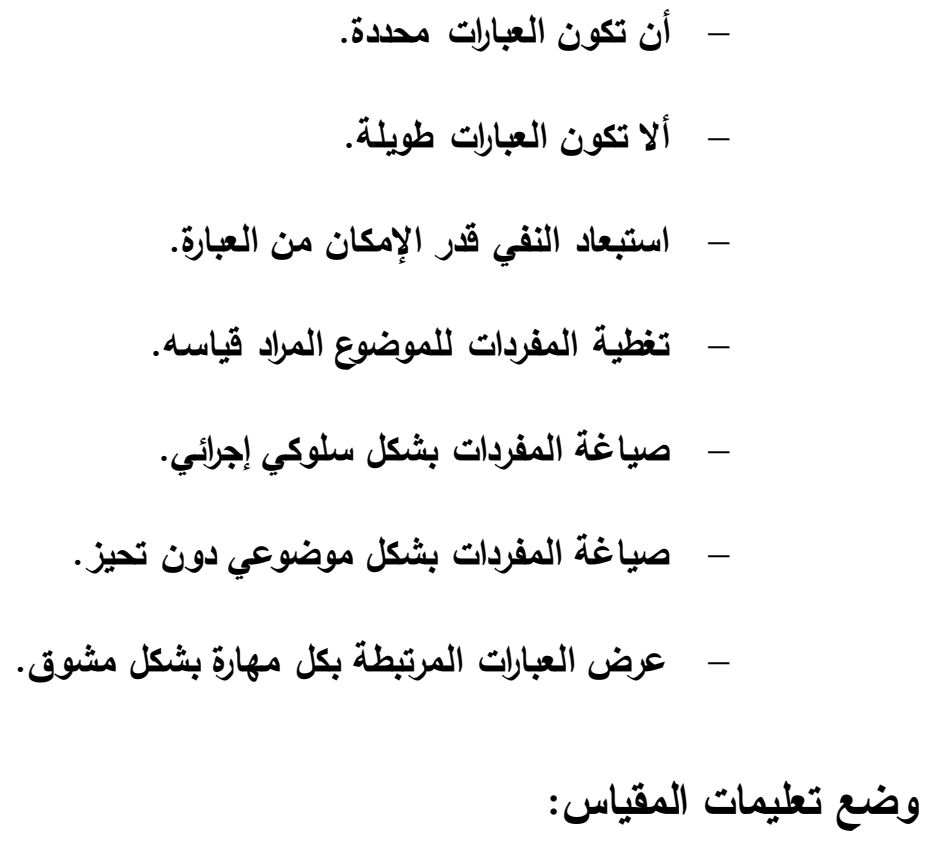
اهتمت الباحثة بوضع تعليمات لمقياس اتخاذ القرار بمهاراته النوعية السبعة والذي قامت بتصميمه، ووضع الصورة النهائية له حيث راعيت في تعليمات المقياس أن 
تكون: (واضحة ـ محدة ـ مباشرة - جيدة ـ مناسبة لمستوي النمو - مرتبطة بالحياة الاجتماعية ـ مرتبطة بالمهارات السبعة لاتخاذ القرار). عزض المقياس على السادة المحكمين: حيث قامت الباحثة بعرض المقياس في صورته المبائية على السادة المحكمين بهف:( تحليد مدي ملائمة المواقف-مدي ملائمة المفردات -مدي صدق المقياس -مدي مناسبة العبارات للشريحة العمرية -مدي وضوح ودقة التعليمات إضافة أو حذف أو تعديل ما يرونه مناسباً)، ولقد أبدي السادة المحكمين عدة ملاحظات استفادت منها الباحثة في إعداد الشكل النهائي للمقياس، وكانت تلك الملاحظات متمثلة في:( حذف بعض المواقف الغير المرتبطة بمهارات اتخاذ القزار - التعديل في صياغة بعض العبارات - إعطاء درجة لكل مهارة بعباراتها حسب التقير الكمي الإيجابي أو السلبي - تحتوي كل مهارة علي ثثلاثة عبارات إيجابية ، وثلاث عبارات سلبية-جعل مقياس تقدير الأداء رباعيا بلل من

يحتوي هذا المقياس على (V) مهارات مرتبط بكل مهارة (T) عبارات فرعية تم توزيعها

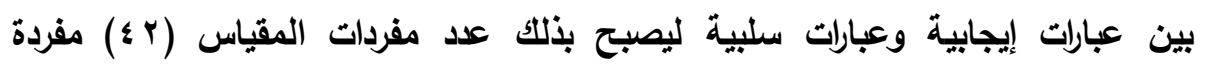

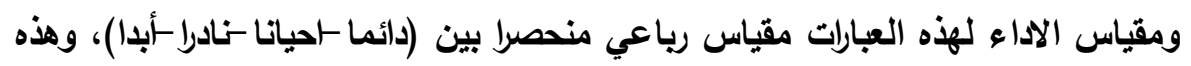
المهارات حسب الجدول التالي:

جدول (r) 
يوضح وصف مقياس اتخاذ القرار

\begin{tabular}{|c|c|c|c|}
\hline \multicolumn{2}{|c|}{ توزيعها } & \multirow{2}{*}{ عدد المفردات } & \multirow{2}{*}{ الآسئلة و المو اقق } \\
\hline سلبي & إيجابي & & \\
\hline$r \leq 610,0$ & $r \cdot 611,1$ & r ج + r س & مهارة تحديد الأهداف \\
\hline 17.167 & $11,1 r \cdot r$ & r ج + r س & مهارة تتظيم البيانات \\
\hline 1161961 . & $I V \cdot V \cdot r$ & r ج + & مهارة تحليل البيانات \\
\hline$r 4$ ، $r r_{6}$ Ir & $1 \leq ، 1 \leq$ & r ج + & مهارة تنمية البدائل \\
\hline$\varepsilon r$ ، $r_{Y}$ ، $r_{0}$ & r & r ج + r س & مهارة تقويم البدائل \\
\hline$\varepsilon \cdot r, r \Lambda$ & $\& 1, r q, r V$ & r ج + r س & مهارة اختيار البديل \\
\hline$r v$ ، r & rA ، rr ، & r ج + r س & مهارة متابعة القراد \\
\hline ri & rl & $\varepsilon r$ & المجموع \\
\hline
\end{tabular}

ومن أجل تحقيق موضوعية المقياس فقد راعت الباحثة الشروط التالية: 
- - - وضوح التعليمات بحيث لا تقبل التأويل. - - التزام طلاب الدرسة الثانوية الفندقية بالزمن المحد للإجابة عن المقياس. - مضوح طريقة تصحيح المقياس بحيث لا يختلف التقير وفق مفتاح التصحيح. - - وضوح أسئلة ومواقف المقياس دون لبس أو غموض.

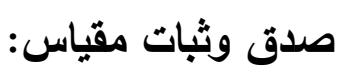

للتحقق من ثبات المقياس، استخدمت الباحثة طريقة إعادة التطبيق على عينة من طلاب الدارس الثانوية الفندقية، تم حساب معامل الثبات ويلفت قيمته (9\%\%) وهي قيمة مرتفعة مما يبل على ان المقياس صالح للتطيق على عينة البحث الأساسية، وللتأكد من الصدق الاخلي، تم حساب معامل الارتباط لمفردات المقياس وحصلت معظم القيم على ارتباط دال موجب، ويهذا يكون قد تم الإجابة عن السؤال الأول للبحث الحالي والذي ينص على: ما مهارات اتخاذ القزار التي يجب تنميتها لاى طلاب الدارس الثانوية القندقية؟ ثانيا: مقياس جواتب الذات الاستثمارية: تم إعداد مقياس جوانب الذات الاستثمارية وفق الخطوات الآتية: تحليد الهذف من المقياس: يهاف إلى قياس مدي توافر جوانب الأات الاستثمارية لاي طلاب الصف الثالث الثانوي الفني الفندقي

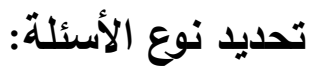


حدت الباحثة عبارات المقياس من خلال ثلاثة أبعاد هي: (الاقتصادي - الاجتماعي -

تحديا مواصفات المقياس:

قامت الباحثة بإعداد جدول مواصفات مقياس جوانب الذات الاستثمارية كما يوضحه

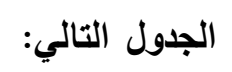

جدول (r)

جول مواصفات مقياس جواتب الذات الاستثمارية

\begin{tabular}{|c|c|c|}
\hline النسبة المئوية & عدد العبارات & المهارة \\
\hline \%rr,o & $\wedge$ & الجاتب الاقتصادي \\
\hline \%rr,o & $\wedge$ & الجانب الاجتماعي \\
\hline \%rr,o & $\wedge$ & الجاتب الاداري \\
\hline$\% 1 \ldots$ & Y $\varepsilon$ & المجموع \\
\hline
\end{tabular}

صدق وثبات المقياس:

تم إعداد المقياس في صورته المبائية وعرضه على مجموعة من

المحكمين لأخذ آرائهم حول: (مدي مناسبة العبارات لكل جانب-مدي ارتباط كل

العبارات بالمستوي الذي تصفه-الاقة العلمية -السلامة اللغوية -حتف أو تعديل

أو إضافة ما ترونه مناسباً)، وقامت الباحثة بإجراء التعليلات المطلوية ليصبح 
المقياس جاهزاً في صورته النهائية ليشمل (؟؟) عبارةً حيث يزتبط كل جانب بثمانية عبارات ليصبح بذلك عدد مفردات المقياس (ع r) مفردة، وقد تم توزيع العبارات على الجوانب الثلاثة لمقياس الأات الاستثمارية. كما يوضحها الجدول التالي:

جذول (飞)

توزيع العبارات على جوانب مقياس الذات الاستثمارية

\begin{tabular}{|c|c|c|}
\hline عدد العبارات & أرقام العبارات & البعد \\
\hline$\wedge$ & $\Lambda-1$ & الجانب الاقتصادي \\
\hline$\wedge$ & $17-9$ & الجانب الاجتماعي \\
\hline$\wedge$ & $r \leqslant-1 V$ & الجانب الاداري \\
\hline$r \varepsilon$ & $r \varepsilon$ & الإجمالي \\
\hline
\end{tabular}

وقا جاءت آراء السادة المحمين لتبرز الاتفاق حول سلامة المقياس ومناسبة

$$
\text { ثفرداته للطلاب. }
$$

اعتمدت الباحثة على طريقة إعادة تطبيق المقياس وفق معادئة "بيرسون" حيث اتضح أن معامل ثبات الاختبار ( 9 \%\%) وهي قيمة عالية يمكن الوثوق فيها، والاطمئنان إلي هذا المقياس ونتائجه في التجربة النهائية، وتم التأكد من الصدق الداخلي، حيث تم 
حساب معامل الارتباط لمفردات المقياس وحصلت معظم القيم على ارتباط دال موجب وهذا يلل على ان المقياس صالح للتطبيق في التجرية الأساسية للبحث، ويهذا يكون قد تم الإجابة عن السؤال الثاني للبحث الحالي والذي ينص على: ما جوانب الذات الاستثمارية التي يجب تنميتها لاى طلاب المدارس الثانوية القندقية؟

ثالثاً: اجراعات تصميم المحتوى التعليمي المدعوم بالواقع الافتراضي: تم تصميم المحتوى التعليمي المدعوم بالواقع الافتراضي لوحدة الاقتصاد والسياحة وفق الخطوات التالية: 1 - اختيار المحتوى التعليمي: تم اختيار المحتوى التعليمي في الوحدة الاولى" السياحة والاقتصاد" من كتاب الاقتصاد للصف الثالث الثانوي بالمدارس الثانوية القنية وقد اشتمل المحتوى التعليمي على الموضوعات التالية: - - التأثيرات الاقتصادية لصناعه السياحة - - - السياحة كظاهرة وصناعه - - التأثيرات الاقتصادية الغير مباشرة للسياحة - - التأثيرات الاقتصادية المباشرة للسياحة - - دور النشاط السياحي في الاقتصاد المصري ولقد تم اختيار هذه هذا المحتوى للاعتبارات الاتية: - - صعوية تدريس هذا المحتوى باستخدام طرق التدريس التقليدية ومن ثم الحاجة الي استراتيجيات تدريس حديثة تعتمد على تكنولوجيا العصر، وهذا ما اتضح من خلال المقابلات الشخصية مع عينة من الطلاب والمعلمين بالمدارس الثانوية 
- تعد وحدة السياحة والاقتصاد مدخلا رئيسا لدراسة جواتب السياحة والاستثمار السياحي والقدرة على ابذاء الرأي، ووجهات النظر وهذا ما يسعى اليه البحث الحالي من تنمية مهارات اتخاذ قرار وجواتب الذات الاستثمارية. - ارتباط هذا المحتوى بأهداف تدريس مادة الاقتصاد بالمرحلة الثانوية القنية كونها تسعي الي تتمية مهارات التفكير، واتخاذ القراد، وتحسين وتتميته جوانب الأتات الاستثمارية وهذا محور اهتمام البحث الحالي. - ارتباط هذا المحتوى بما تتادي به وزارة التربية والتعليم من ضرورة الاهتمام بتعليم التفكير واستراتيجيات تدريسه بدلا من الحفظ والاستظهار والتخلص من فكرة التعلم القائم على حشو العقول إلى تعلم مباع وإبتكاري. - ارتباط هذا المحتوى بروئية مصر (2030) والتي تركز على قطاع الاستثمار وخاصة الاستثمار السياحي من أجل اعادة مصر إلى مكانتها الطبيعية.

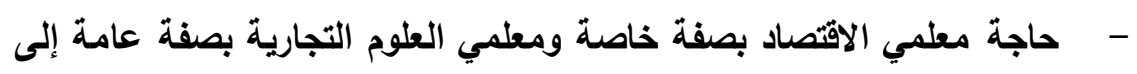
استخدام تكنولوجيا العصر وتطبيقات الواقع الافتراضي في التريس. ץ-تحليل المحتوى: تم تحليل محتوى الوحدة الدراسية "الاقتصاد والسياحة" لاستخراج قائمة بالمعارف ومهارات استخدامها، وقد التزم البحث الحالي بالتعريفات الاتية لفئات التحليل أثناء اجراء عملية التحليل لوحدة (السياحة والاقتصاد). - الحقيقة: وتعنى كل ما هو صحيح وينطبق على الواقع أو ما يتفق عليه العقل والمنطق ويالتالي هنا الحقيقة الواقعية والحقيقة المنطقية والعقلية. - المفهوم: هو تصور يتكون لاى الطالب عن مجموعة خصائص ترتبط بكلمة او مصطلح، ويعتبر تجريدا للعناصر المشتركة بين عدة مواقف، وعادة ما يعطى 
- المبدأ أو التعميم: هو علاقة بين مفهومين أو أكثر، ويعبر عنه عادة بجملة شرطية، وقد يأخذ المبدأ شكل التعيم فيضم أكثر من حقيقة. - القوانين: تشبه المبادئ من حيث أتها تضم عددا من المفاهيم وتحدد العلاقات بينها، لكنها تعد أكثر تحديدا للعلاقات بين المفاهيم وتتسم بلرجة اعلى من الثبات، ولهذا سواء كان القانون كميا او كيفيا فانه يصف ظاهرة ثابتة في الطبيعة، أما في مجال الاقتصاد فالقوانين كمية (قوانين احصائية تعتمد على التحليل الكمي، وقوانين كيفية منطقية تعتمد على الملاحظة والاستنتاج. - النظريات: عبارة عن تكوينات فرضية وتصورات ذهنية تؤيدها بعض المشاهدات

$$
\text { والتجارب العملية }
$$

r-ثبات التحليل: ولقياس مدى ثبات عملية التحليل بالنسبة لمحتوى وحدة الاقتصاد والسياحة تم استخدام طريقة اعادة التحليل التي تعتمد على اجراء التحليل مرتين على المحتوى نفسه بفاصل زمنى مناسب، وتحليد العلاقة بينهما من خلال مؤشر الثبات في شكل درجة معينة، وقد قامت الباحثة بتحليل نفس المحتوى العلمي مرتين متتاليتين ويفاصل زمنى ثلاثة أسابيع، ويعد الانتهاء من التحليل الثاني طبقت معادلة هولستى لبيان العلاقة بين النتائج في التحليلين ، ومن ثم الوصول الى نسبة الاتفاق بين عمليتي التحليل والتي تعد مؤشرا الثبات التحليل الخاص بالمحتوى.(رشدي طعيمه ،1987) 
جلول (•)

نتائج حساب تحليل المحتوي

\begin{tabular}{|c|c|c|c|c|}
\hline معامل الثبات & المداد المفردات & في & عل & المحتوي \\
\hline$\% q 0.9$ & $1 \cdot V$ & 110 & $1 \cdot V$ & المبادئ والتقائق ـ المفاهيم - التعيمات - \\
\hline
\end{tabular}

ومن هذا الجدول اتضح أن معامل الثبات في هذه الحالة يعد مرتفعاً حيث يساوي

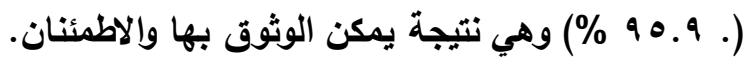


؛ - صدق التحليل: اعتمد صدق التحليل في البحث الحالي علي "صدق المحتوي"

حيث تم عرض قائمة تحليل المحتوي التي أعدتها الباحثة علي مجموعة من

الاختصاصين، وقت اشتملت هذه المجموعة عدد من الأساتذة المتخصصين في

مجال المناهج وطرق التدريس ، ويعض موجهي العلوم التجارية ، وكاتت

النتائج متفقة مع ما توصلت إليه الباحثة من فئات التحليل المتمثلة في

(الحقائق - المفاهيم - المبادئ والتعميمات ـ القوانين والنظريات)، ويالتالي

اعتمدت الدراسة الحالية هنا علي صدق المحكمين حول فئات التحليل.

ه -تصميم وإنتاج برنامج الكمبيويز القائم على الواقع الافتراضي:

تم صميم وإنتاج برنامج الكمبيوتز القائم على الواقع الافتراضي وفق

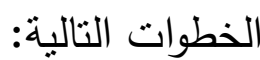

مرحلة التصميم: - مل

"سعت هذه المرحلة إلى وضع تصوراً كاملاً لمشروع البرنامج وما ينبفي أن

يحتويه وفقاً للخطوات التالية:

- - تحليد الهـف العام والاهداف التفصيلية التي يسعى البرنامج لتحقيقها.

- اختيار المحتوي وإعداده: وقع اختيار الباحثة على الموضوعات

المتضمنة في الوحدة الأولي من كتاب الاقتصاد للصف الثالث الثانوي

الفني الفندقي وهي بعنوان (السياحة والاقتصاد). تم تنظيم المحتوي

العلمي لموضوعات الوحدة إلى مجموعة من الاروس، وتم صياغة 
الأهداف الإجرائية للبرنامج وتضمينها في البرنامج، وإختيار نوع التقويم

داخل البرنامج والمتمثل في الاختيار من متعدد، ويعض أسئلة المقال. - اعداد السيناريو الخاص بتقديم موضوعات الوحدة "السياحة والاقتصاد" موضوع البحث الحالي في ضوء استراتيجية ماكفرلاند المدعومة بالواقع الاقتراضي، وهي عبارة عن شكل الشاشات الرئيسية والفرعية لعناصر المحتوى وخصائصها الفنية ومحتواها العلمي، وقا روعي في كتابة السيناريو: (احتواء كل شاشة على فكرة أو فقرة واحدة -تسلسل الانتقال من السهل إلى الصعب -وضوح الأهداف الخاصة بكل درسإمكانية التحمم في الانتقال من شاشة إلى أخري أثناء العرض -إمكانية التحكم في الصوت). مع مراعاة ملائمة تلك الثاشات بما تتضمنه من وسائط تعليمية (النصوص المكتوية والمنطوقة ـ الصور والرسوم الثابتة ، الرسوم التخطيطية، لقطات القيديو) لأهداف البرنامج وطبيعة المادة، وتحديد أسلوب التفاعل بين المتعلم والبرنامج، وإعداد الأيقونات التي تتمثل في:( التقدم للأمام -الرجوع للخلف - الرجوع للقائمة الرئيسية الخروج من البرنامج) حيث يكتب في كل أيقونة اسم الوظيفة التي تؤديها بحيث تؤدي وظيفتها عند النقر أو التأشير عليها ويالتالي تمكن المستخدم من التجوال داخل البرنامج والرجوع للقائمة الرئيسية أو

$$
\text { انهاء البرنامج. }
$$
- اعداد دليل المعلم: تم اعداد دليل المعلم في صورته الأولية، بحيث يحتوي على الأهداف السلوكية لكل درس من دروس الوحدة مصاغة 
بشكل اجرائي محد، خطة السير في الارس، التقويم، وتم عرض الدليل على مجموعة من الاختصاصين، وتم اجراء التعديلات في ضوء ملاحظاتهم والتي تمثلت في تعديل صياغة بعض الأهداف، تتضمن خطة سير الدرس (التمهيد - الثرح - الأنثطة - التقويم). - اعداد التقويم النهائي لأداء الطلاب والذي يتمثل في مقياسي اتخاذ القرار، والذات الاستثمارية للتعرف على مدي فاعلية البرنامج في تحقيق أهدافه. - عرض البرنامج في صورته الأولية على مجموعة من الاختصاصين في مجال المناهج وطرق التريس وتكنولوجيا التعليم والمعلومات، والاخذ بملاحظاتهم والتي كاتت أهمها تعديل بعض الأهداف الخاصة ببعض الدرس لتصبح أكثر إجرائية، توضيح أساليب التقويم لكل درس، اثراء البرنامج بمزيد من كائنات التعلم الرقمية لقطات الفيديو، والأنشطة التعليمية المدعمة بالتظنية الراجعة ، وتسير استراتيجية التدريس المستخدمة استراتيجية ماكفرلاند باية من التمهيذ من خلال طرح سؤال او نشاط متنوع مرتبطا بقصة مثيرة او لقطات فيليو او صول يتضمن مجموعة من الكلمات المترايطة المتعلقة بموضوع الدرس مع وجود كلمة مختلة يبأ المتعلم بتحليد الكلمات المرتبطة وغير المرتبطة من خلال المناقشات الجماعية ، ويرتب الكلمات في جمل مترايطة ويحدد الموضوع ، حيث يقوم كل طالب بالتشاور حول الكلمة 
الوحيدة المختلفة وتقديم وجهة نظر منطقية لكل مجموعة ، ثم التقويم

التكويني ، وتقويم في نهاية كل موضوع.

مرحلة التطوير

تم تطوير البرنامج بمزيد من كائنات التعلم الرقمي ولقطات الفيليو، وروابط

فرعية للأنشطة التعليمية، بحيث تضمن البرنامج (†) شاشات رئيسية هي: (شاشة

التعريف بالبرنامج -شاشة القائمة الرئيسية مشاشة ترتيب الارس وغنوانه مثاشة

الأهداف الخاصة بكل درس -شاشة عرض المحتوي -شاشة التقويم). بناءًٌ على

ملاحظات الاختصاصين في مجال تكنولوجيا التعليم.

مرحلة التنفيذ

هافت هذه المرحلة الى التحقق من مدى صلاحية البرمجية للاستخدام والتطبيق،

وتم هذا من خلال تجهيز البيئة المدرسية وتدريب الطلاب على التعامل مع البرمجية،

وتدريس البرمجية كتجريب اولي على عينة ممثلة للفئة المستهفة وذلك من اجل

التحسين والتطوير.

مرحلة التقويم

هافت مرحلة التقويم الى إجراء التعديلات اللازمة والتي نتجت عن التجريب

الأولي، لتكون البرمجية صالحة للتطبيق على العينة الأساسية، ويهذا يكون قد تم الإجابة عن السؤال الثالث من أسئلة البحث الحالي الأي ينص على: ما التصور لوحدة معاد صياغتها في مادة الاقتصاد لطلاب المدارس الثانوية الفندقية باستخدام استراتيجية ماكفرلاند المدعومة بالواقع الافتراضي. 


$$
\text { التجريب الميداني: }
$$

هدف الى قياس فاعلية استخدام استراتيجية ماكفرلاند المدعومة بالواقع الافتراضي في تدريس منهج الاقتصاد على تتمية مهارات اتخاذ القرار والذات الاستثمارية لدى طلاب الددارس الثانوية الفندقية، ولتحقيق هذا الهذف تم تنفيذ الخطوات التالية: - تصليد الخطة الزمنية لتدريس موضوعات الوحدة المختارة وفق استراتيجية ماكفرلاند حيث استعانت الباحثة بخطة توزيع المنهج التي أعدتها الوزارة كما أنها أخذت بعض الحصص الاضافية من معلمي المواد الأخرى والأنشطة ليتم تدريس البرنامج بواقع (0 1 ) حصة. - - تطبيق أدوات البحث تطبيقا قبليا (مقياس مهارات اتخاذ القرار، مقياس الذات الاستثمارية) على عينة البحث (المجموعة التجريبية والضابطة) التي تم تحديدها سابقا. - تدريس للوحدة الأولي من مقر الاقتصاد للصف الثالث الثانوي الفندقي وهي بعنوان السياحة والاقتصاد "على الطلاب الممثلين لعينة الدراسة وذلك يوم

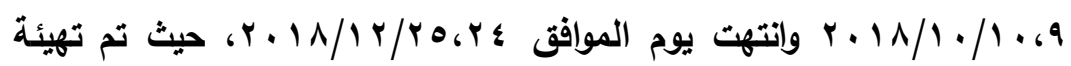
الطلاب من خلال جلسات تمهيدية وارسال رايط البرنامج وتدريبهم على كيفية الاخول والتعامل مع الروابط، وكيفية التتقل بين روابط كل موضوع من موضوعات الوحدة وفتح لقطات الفيليو الخاصة بكل موضوع وانهائها والتعامل مع الأنشطة التعليمية وتلقي التظذية الراجعة وفق عدد الحصص المخصص. - تطبيق أدوات القياس تطبيقا بعديا على عينة البحث. 
- رصد النتائج في جذاول لأجراء التحليلات الإحصائية المناسبة، وتدوين النتائج بهاف استخلاص فاعلية تعليم موضوعات وحدة السياحة والاقتصاد من خلال استراتيجية ماكفرلاند المدعومة بالواقع الافتراضي على مهارات اتخاذ القراد وتنمية الذات الاستثمارية، وقد استخدم البحث مزيجا من الأساليب الإحصائية والوصفية والاستدلالية كما سيتضح في الجزء الخاص بنتائج البحث. نتائج البحث: أولا: النتائج المتعلقة بالفرض الأول: ينص الفرض الأول للبحث على: لا يوجد فرق دال احصائيا عند مستوى دلالة (0.05) بين متوسطات درجات طلاب المجموعتين الضابطة والتجريبية على مقياس مهارات اتخاذ القزار في التطبيق القبلي والبعدي. وللتحقق من صخة هذا الفرض استخدمت الباحثة إجراءات التحليل الاحصائي المرتبطة باختبارات T-Test للكشف عن دلالة الفرق بين المتوسطات باستخدام برنامج SPSS، ويوضح الجدول التالي عرض تفصيلي وصفي واستدلالي لنتائج التطبيق البعدي لمقياس مهارات اتخاذ القزار

$$
\text { جلول (7) (7) - (7) }
$$

قيمة ت، ودلالتها الإحصائية للفرق بين متوسطي درجات طلاب المجموعتين (ض ، ت ) في التطبيق البعدي لمقياس مهارات اتخاذ القرال

\begin{tabular}{|c|c|c|c|c|c|c|c|}
\hline حجم الفاعلية & مستوي & قيمة "ت" & الانحراف & المتوسط & الدارجة & المجموعات & البيانات \\
\hline ونوعه & الدلالة & & المعياري & الحسابي & التهائية & & اتخاذ القرار ومهاراته \\
\hline
\end{tabular}




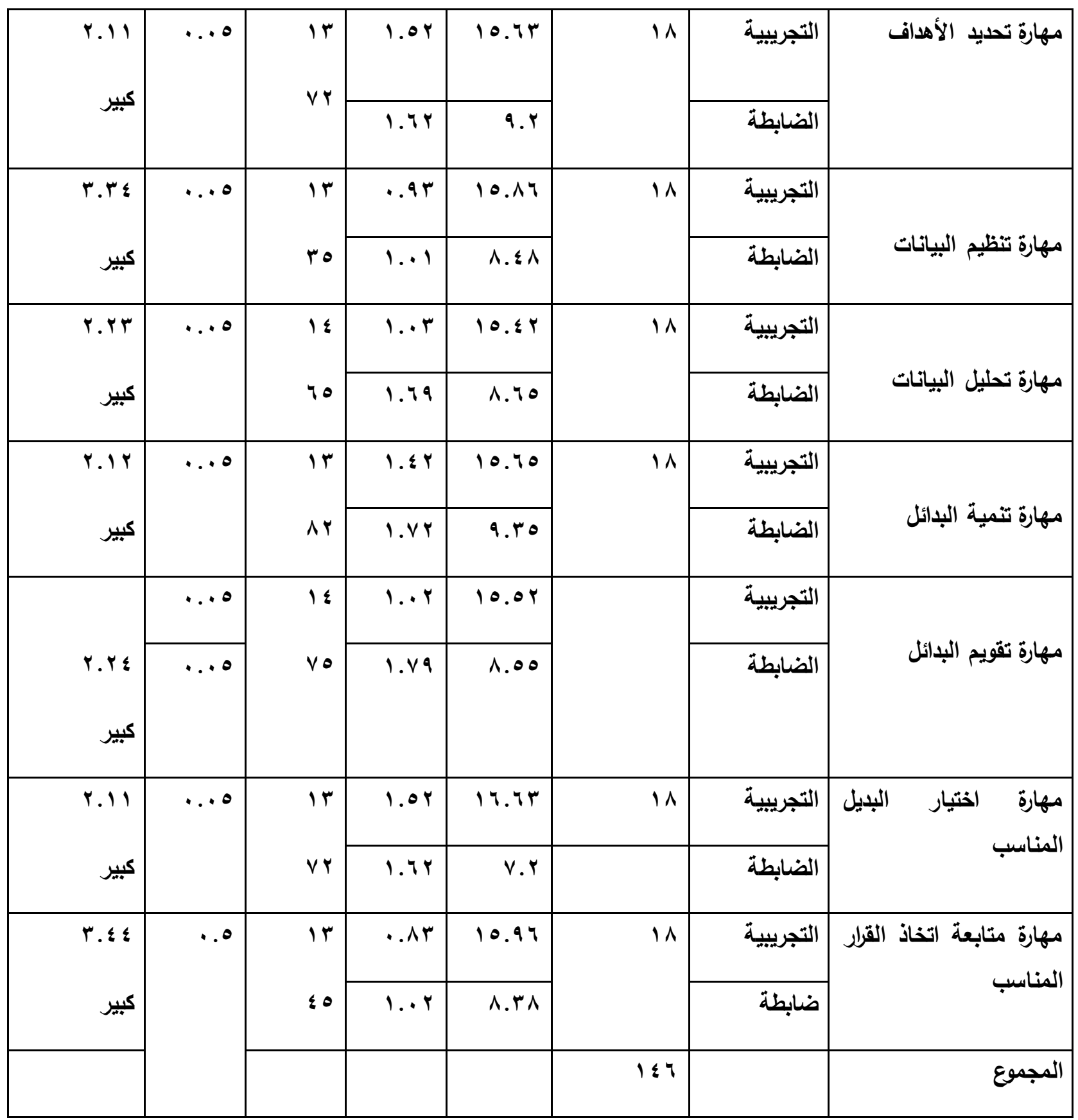

يتضح من جدول (†) السابق ما يلي: 
- تفوق أداء المجموعة التجريبية على المجموعة الضابطة، حيث بلغ متوسط المجموعة التجريبية في التطبيق البعدي لمهارة تحديد الأهداف أحد مهارات اتخاذ القزار(15.63) باتحراف معياري (1.52) مقابل متوسط (9.2) باتحراف معياري (1.62) للمجموعة الضابطة. - - كما يتضح وجود فرق دال إحصائياً عذ مستوي دلالة (0.05) لصالح طلاب المجموعة التجريبية في التطبيق البعدي لمهارة تحديد الأهداف احدى مهارات اتخاذ القرار لصالح المجموعة التجريبية، حيث بلغت قيمة ت (13) ، ويلغ حجم التأثير أو الفاعلية للمتغير المستقل (استراتيجية ماكفرلاند المدعومة بالواقع الافتراضي ) على المتغيرات التابعة (مهارات اتخاذ القزار، وتتمية الذات الاستثمارية) (2.11) ، وهذا يعد حجم كبير، مما يؤكد تفوق المجموعة التجريبية علي الضابطة في مقياس اتخاذ القرار - تحسن أداء المجموعة التجريبية على المجموعة الضابطة، حيث بلغ متوسط المجموعة التجريبية في التطبيق البعدي لمهارة تنظيم البيانات أحد مهارات اتخاذ القزار(15.86) بانحراف معياري (93.) مقابل متوسط (8.48) باتحراف معياري (1.01) (للمجموعة الضابطة. - وجود فرق دال إحصائياً عن مستوي دلالة (0.05) لصالح طلاب المجموعة التجريبية في التطبيق البعدي لمهارة تنظيم البيانات احدى مهارات اتخاذ القراد لصالح المجموعة التجريبية، حيث بلغت قيمة ت (13) ، ويلغ حجم التأثير أو الفاعلية للمتغير المستقل (استراتيجية ماكفرلاند المدعومة بالواقع الافتراضي ) 
على المتغيرات التابعة (مهارات اتخاذ القرار، وتتمية الذات الاستثمارية) (3.34) ، وهذا يعد حجم كبير، مما يؤكد تفوق المجموعة التجريبية علي الضابطة في مقياس اتخاذ القرار. - - تسن أداء المجموعة التجريبية على المجموعة الضابطة، حيث بلغ متوسط المجموعة التجريبية في التطبيق البعدي لمهارة تحليل البيانات أحد مهارات اتخاذ القرار(15.42) بانحراف معياري (1.03) مقابل متوسط (8.65) باتحراف معياري (1.69) للمجموعة الضابطة. - وجود فرق دال إحصائياً عند مستوي دلالة (0.05) لصالح طلاب المجموعة التجريبية في التطبيق البعدي لمهارة تحليل البيانات احدى مهارات اتخاذ القرار لصالح المجموعة التجريبية، حيث بلغت قيمة ت (14) ، ويلغ حجم التأثير أو الفاعلية للمتغير المستقل (استراتيجية ماكفرلاند المدعومة بالواقع الافتراضي ) على المتغيرات التابعة (مهارات اتخاذ القرار، وتتمية الذات الاستثمارية) (2.23) ، وهذا يعد حجم كبير، مما يؤكد تفوق المجموعة التجريبية علي الضابطة في مقياس اتخاذ القرار. - تفوق المجموعة التجريبية على المجموعة الضابطة، حيث بلغ متوسط المجموعة التجريبية في التطبيق البعدي لمهارة تتمية البدائل أحد مهارات اتخاذ القرار(15.65) بانحراف معياري (1.42) مقابل متوسط (9.35) باتحراف معياري (1.72) للمجموعة الضابطة. 
- كما يتضح وجود فرق دال إحصائياً عذ مستوي دلالة (0.05) لصالح طلاب المجموعة التجريبية في التطبيق البعدي لمهارة تتمية البدائل احدى مهارات اتخاذ القرار لصالح المجموعة التجريبية، حيث بلغت قيمة ت (13) ، ويلغ حجم التأثير أو الفاعلية للمتغير المستقل (استراتيجية ماكفرلاند المدعومة بالواقع الافتراضي ) على المتغيرات التابعة (مهارات اتخاذ القرار، وتنمية الذات الاستثمارية) (2.12) ، وهذا يعد حجم كبيز، مما يؤكد تفوق المجموعة التجريبية علي الضابطة في مقياس اتخاذ القرار. - تفوق أداء المجموعة التجريبية على المجموعة الضابطة، حيث بلغ متوسط المجموعة التجريبية في التطبيق البعدي لمهارة تقويم البدائل أحد مهارات اتخاذ القرار(15.52) بانحراف معياري (1.02) مقابل متوسط (8.55) باتحراف معياري (1.79) للمجموعة الضابطة. - وجود فرق دال إحصائياً عن مستوي دلالة (0.05) لصالح طلاب المجموعة التجريبية في التطبيق البعدي لمهارة تقويم البدائل احدى مهارات اتخاذ القرار لصالح المجموعة التجريبية، حيث بلغت قيمة ت (14)، ويلغ حجم التأثير أو الفاعلية للمتغير المستقل (استراتيجية ماكفرلاند المدعومة بالواقع الافتراضي) 2. ) على المتغيرات التابعة (مهارات اتخاذ القرار، وتتمية الذات الاستثمارية) 24) ، وهذا يعد حجم كبير، مما يؤكد تفوق المجموعة التجريبية علي الضابطة في مقياس اتخاذ القرار. 
- تحسن أداء المجموعة التجريبية على المجموعة الضابطة، حيث بلغ متوسط المجموعة التجريبية في التطبيق البعدي لمهارة اختيار البديل أحد مهارات اتخاذ القرار(16.63) بانحراف معياري (1.52) مقابل متوسط (7.2) باتحراف معياري

(1.62) - ل امجموعة الضابطة. - كما اتضح وجود فرق دال إحصائياً عذ مستوي دلالة (0.05) لصالح طلاب المجموعة التجريبية في التطبيق البعي لمهارة اختيار البديل احدى مهارات اتخاذ القزار لصالح المجموعة التجريبية، حيث بلغت قيمة ت (13) ، ويلغ حجم التأثير أو الفاعلية للمتغير المستقل (استراتيجية ماكفرلاند المدعومة بالواقع الافتراضي ) على المتغيرات التابعة (مهارات اتخاذ القرار، وتنمية الذات الاستثمارية) (2.11) ، وهذا يعد حجم كبير، مما يؤكد تفوق المجموعة التجريبية علي الضابطة في مقياس اتخاذ القزار. - تفوق المجموعة التجريبية على المجموعة الضابطة، حيث بلغ متوسط المجموعة التجريبية في التطبيق البعدي لمهارة متابعة اتخاذ القرار أحد مهارات اتخاذ القزار(15.96) بانحراف معياري (83.) مقابل متوسط (8.38) بانحراف معياري (1.02) للمجموعة الضابطة. - وجود فرق دال إحصائياً عند مستوي دلالة (0.05) لصالح طلاب المجموعة التجريبية في التطبيق البعدي لمهارة متابعة اتخاذ القرار احدى مهارات اتخاذ القرار لصالح المجموعة التجريبية، حيث بلغت قيمة ت (13) ، ويلغ حجم التأثير أو الفاعلية للمتغير المستقل (استراتيجية ماكفرلاند المدعومة بالواقع 
الافتراضي ) على المتغيرات التابعة (مهارات اتخاذ القرار، وتنمية الذات الاستثمارية) (3.44) ، وهذا يعد حجم كبيز، - - يتضح من النتائج السابقة تفوق المجموعة التجريبية على الضابطة في مهارات اتخاذ القرار. واستتاداً لما سبق يمكن رفض الفرض الصفري القائل بانه لا يوجد فرق دال احصائيا عند مستوى دلالة (0.05) بين متوسطات درجات طلاب المجموعتين الضابطة والتجريبية على مقياس مهارات اتخاذ القرار في التطبيق القبلي والبعدي، وقبول الفرض البديل القائل بأنه يوجد فرق دال إحصائياً عذ مستوي دلالة (0.05) بين متوسطات درجات المجموعتين الضابطة والتجريبية على مقياس اتخاذ القرار ا (بجميع مهاراته الفرعية) لصالح المجموعة التجريبية في التطبيق البعدي، ويالتالي يكون قد تم الاجابة على السؤل الرايع من اسئلة البحث والأي ينص على : ما فاعلية استراتيجية ماكفرلاند المدعومة بالواقع الافتراضي في تدريس مادة الاقتصاد على تنمية مهارات اتخاذ القرار لاى طلاب المدرسة الثانوية القندقية؟ ثانيا: التتائج المتعقة بالفرض الثاني: ينص الفرض الثاني للبحث على: لا يوجد فرق دال احصائيا عند مستوى دلالة ( 0.05) بين متوسطات طلاب المجموعتين الضابطة والتجريبية على مقياس جوانب الذات الاستثمارية في التطبيق القبلي والبعدي ،وللتحقق من صحة هذا الفرض استخدمت الباحثة إجراءات التحلي الاحصائي المرتبطة باختبارات T-Test للكشف عن دلالة الفرق 
بين المتوسطات باستخدام برنامج SPSS، ويوضح الجدول التالي عرض تفصيلي وصفي واستدلالي لنتائج التطبيق البعدي لمقياس مهارات اتخاذ القرار

جلول (v)

قيمة ت، ودلالتها الإحصائية للفرق بين متوسطي درجات طلاب المجموعتين (ض، ت) في التطبيق البعدي لمقياس جوانب الذات الاستثمارية (الجانب الاقتصادي).

\begin{tabular}{|c|c|c|c|c|c|c|c|}
\hline الدلالة & "ت & الحرجات & الانحراف & المتوسط & العدد & المجموعة & الجانب \\
\hline دالة & IY. $\leqslant 7$ & $\begin{array}{l}71 \\
71\end{array}$ & $\begin{array}{l}1 . .1 \\
1.41\end{array}$ & $\begin{array}{l}T . Y \Lambda \\
\text { T.rT }\end{array}$ & $\begin{array}{l}r . \\
r .\end{array}$ & التجريبية & الاقتصادي \\
\hline
\end{tabular}

يتضح من جدول (V) السابق ما يلي:

- تفوق المجموعة التجريبية على المجموعة الضابطة، حيث بلغ متوسط

المجموعة التجريبية في التطبيق البعدي في الجانب الاقتصادي لمقياس تتمية

جوانب الذات الاستثمارية(6.28) باتحراف معياري (1.01) مقابل متوسط

(3.32) باتحراف معياري (1.21) للمجموعة الضابطة.

- وجود فرق دال إحصائياً عذ مستوي دلالة (0.05) لصالح طلاب المجموعة

التجريبية في التطبيق البعدي في الجاتب الاثتصادي لمقياس تنمية جواتب الذات

الاستثمارية لصالح المجموعة التجريبية، حيث بلغت قيمة ت عذد درجات حرية 
61 المدعومة بالواقع الافتراضي) على المتغير التابع (تنمية الذات الاستثمارية).

$$
\text { (^) (^ل) }
$$

قيمة ت، ودلالتها الإحصائية للفرق بين متوسطي درجات طلاب المجموعتين (ض، ت)

في التطبيق البعدي لمقياس جواتب الذات الاستثمارية (الجانب الاجتماعي).

\begin{tabular}{|c|c|c|c|c|c|c|c|}
\hline مستوي & "تيمة & لدرجات & الانحراف & المتوسط & العدد & المجموعة & الجانب \\
\hline دالة & $17.7 \leq$ & 71 & $\begin{array}{l}1 . r \varepsilon \\
1 . v .\end{array}$ & $\begin{array}{r}7.8 \\
7.99\end{array}$ & $\begin{array}{l}r . \\
r .\end{array}$ & الضجريبية & الاجتبانب \\
\hline
\end{tabular}

\section{يتضح من جدول (^) السابق ما يلي:}

- تفوق المجموعة التجريبية على المجموعة الضابطة، حيث بلغ متوسط

المجموعة التجريبية في التطبيق البعدي في الجاتب الاجتماعي لمقياس تتمية

جوانب الذات الاستثمارية(6.7) بانحراف معياري (1.34) مقابل متوسط

(3.99) بانحراف معياري (1.70) للمجموعة الضابطة.

- وجود فرق دال إحصائياً عند مستوي دلالة (0.05) لصالح طلاب المجموعة

التجريبية في التطبيق البعدي في الجاتب الاجتماعي لمقياس تنمية جواتب الذات

الاستثمارية لصالح المجموعة التجريبية، حيث بلغت قيمة ت عذد درجات حرية 
61

المدعومة بالواقع الافتراضي) على المتغير التابع (تنمية الذات الاستثمارية).

\section{جدول (9)}

قيمة ت، ودلالتها الإحصائية للفرق بين متوسطي درجات طلاب المجموعتين (ض، ت)

في التطبيق البعدي لمقياس جواتب الأات الاستثمارية (الجاتب الاداري)

\begin{tabular}{|c|c|c|c|c|c|c|c|}
\hline مستوي الدلالة & "تيمة & درجات & الانحراف & المتوسط & العدد & المجموعة & الجانب \\
\hline دالة & $1 \varepsilon . Y$ & 71 & $\begin{array}{l}1 . r T \\
1 . V V\end{array}$ & $\begin{array}{r}7.1 \\
r .99\end{array}$ & $\begin{array}{r}r . \\
\text { r. }\end{array}$ & الضنابطة & الادانب \\
\hline
\end{tabular}

يتضح من جدول (9) السابق ما يلي:

- تفوق المجموعة التجريبية على المجموعة الضابطة، حيث بلغ متوسط

المجموعة التجريبية في التطبيق البعدي في الجاتب الاداري لمقياس تتمية

جوانب الذات الاستثمارية(6.3) بانحراف معياري (1.32) مقابل متوسط

(2.99) باتحراف معياري (1.77) للمجموعة الضابطة.

- وجود فرق دال إحصائياً عند مستوي دلالة (0.05) لصالح طلاب المجموعة

التجريبية في التطبيق البعدي في الجانب الاداري لمقياس تتمية جوانب الذات

الاستثمارية لصالح المجموعة التجريبية، حيث بلغت قيمة ت عند درجات حرية 
61

المدعومة بالواقع الافتراضي ) على المتفير التابع (تتمية الذات الاستثمارية) . - - يتضح من النتائج السابقة تفوق المجموعة التجريبية على الضابطة في مقياس تنمية جواتب الذات الاستثمارية. واستتاداً لما سبق يمكن رفض الفرض الصفري القائل بانه لا يوجد فرق دال احصائيا عند مستوى دلالة (0.05) بين متوسطات درجات طلاب المجموعتين الضابطة والتجريبية على مقياس تنمية جوانب الذات الاستثمارية في التطبيق القبلي والبعدي، وقبول الفرض البديل القائل بأنه يوجد فرق دال إحصائياً عند مستوي دلالة (0.05) بين متوسطات درجات المجموعتين الضابطة والتجريبية على مقياس تنمية الذات الاستثمارية (بجوانبه الثلاثة :الاقتصادي ،الاجتماعي ،الاداري) لصالح المجموعة التجريبية في التطبيق البعدي، ويالتالي يكون قد تم الاجابة على السؤال الخامس من اسئلة البحث والذي ينص على: ما فاعلية استراتيجية ماكفرلاند المدعومة بالواقع الافتراضي في تدريس مادة الاقتصاد على تنمية جوانب الذات الاستثمارية لاى طلاب المدراس الثانوية القندقية؟

\section{مناقشة النتائج}

- - توصل البحث الحالي الى تصميم مقياس لقياس مهارات اتخاذ القرار اللازمة لطلاب الصف الثالث الثانوي الفني الفندقي، يحتوي هذا المقياس على (V) مهارات مرتبط بكل مهارة (†) مهارات فرية تم توزيعها بين عبارات إيجابية وعبارات سلبية ليصبح بذلك عدد مفردات المقياس (ץ ع) مفردة. 
- توصل البحث الحالي الى تصميم مقياس لقياس جواتب الذات الاستثمارية:(الجاتب الاقتصادي، الجانب الاجتماعي، الجانب الإداري) اللازمة لطلاب الصف الثالث الثانوي القني القندقي، يرتبط كل جانب من جوانب الذات الاستثمارية بثمانية عبارات ليصبح بذلك عدد مفردات المقياس ( ؟ ب) مفردة. - - كما توصل البحث الحالي الى تصميم برمجية لتدريس موضوعات وحدة الاقتصاد والسياحة باستخلام استراتيجية ماكفرلاند المدعومة بالواقع الافتراضي، وتتضمن الوحدة (4) موضوعات، وقد تم صياغة المحتوى في شكل رقمي بتضمن مجموعة من الوسائط، والنصوص والصور، ولقطات الفيليو، مع ترك حرية التتقل للمتعلم داخل شاشات البرمجية، وتقيم تغذية راجعة فورية للمتعلم. - كما أظهرت نتائج البحث الحالي ان استراتيجية ماكفرلاند المدعومة بالواقع الافتراضي في تدريس وحدة الاقتصاد والسياحة ساعدت على تنمية مهارات اتخاذ القرار لاى طلاب المدارس الثانوية القندقية حيث أظهرت النتائج وجود فروق ذات دلالة إحصائية بين متوسطي درجات طلاب المجموعتين التجريبية والضابطة على مقياس مهارات اتخاذ القرار لصالح المجموعة التجريبية التي درست باستخدام استراتيجية ماكفرلاند المدعومة بالواقع الافتراضي ، وقت ارجعت الباحثة ذلك الى ان استراتيجية ماكفرلاند المدعومة بالواقع الافتراضي في تدريس وحدة الاقتصاد والسياحة كان لها بالغ الأثر في تنمية مهارات اتخاذ القرار، حيث ان توظيف الوسائط المتعدة، وكائنات التعلم الرقمية ساعد على طرح نماذج اقتصادية وسياحية جليدة لم يتم التطرق لها من قبل، حيث تم ربط المحتوى بالواقع ومتطلبات العمل في مجال السياحة، واثر السياحة على الاقتصاد، كما ان تقديم المحتوى بشكل متسلسل ومنطقي ساعد على جذب انتباه الطلاب وزيادة دافعيتهم للتعلم وميلهم الى الاستقلال ، والقدرة على اتخاذ القرار ، مما كان لله

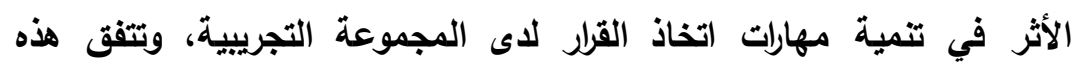
النتيجة مع نتائج بعض الدراسات والبحوث السابقة والتي تتاولت استخدام استراتيجية ماكفرلاند في تتمية مهارات التفكير في مختلف المجالات ـ منها 
دراسة الحوري وآخرون(2009)، ، دراسة سويد (2013)، ودراسة

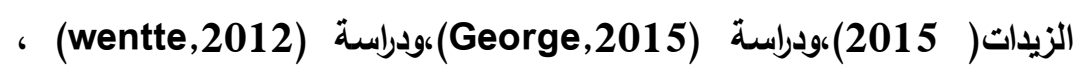
كما اتفقت هذه النتائج مع الداسات التي تناولت تصميم الواقع الافتراضي مثل دراسة عواد (2012) ، ودراسة السلاموني (2014)، ودراسةعبد العزيز ، فوده

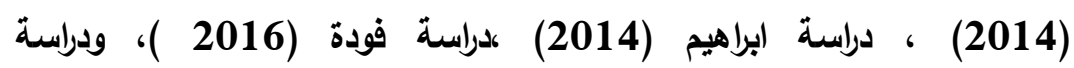
(Varshney \& etc,2018) (Duel,2017) الدراسات التي تتاولت تصميم الواقع الافتراضي وقياس فاعليته على مهارات

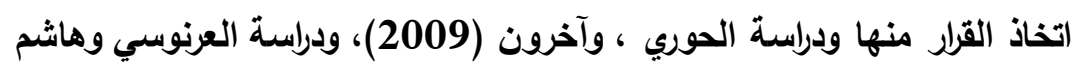

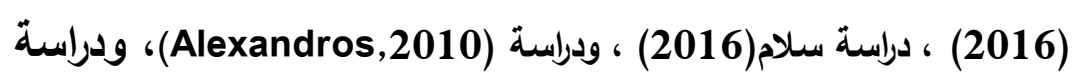

(Fredirck, 2014) الافتراضي في تدريس وحدة الاقتصاد والسياحة ساعت على تنمية جوانب الذات الاستثمارية لاى طلاب الدارس الثانوية الفندقية حيث أظهرت النتائج وجود فروق ذات دلالة إحصائية بين متوسطي درجات طلاب المجموعتين التجريبية والضابطة على مقياس جواتب الأت الاستثمارية لصايح المجموعة التجريبية التي درست باستخدام استراتيجية ماكفرلاند المدعومة بالواقع الاقتراضي ، وقا ارجعت الباحثة ذلك الى ان استراتيجية ماكفرلاند المدعومة بالواقع الافتراضي في تدريس وحدة الاقتصاد والسياحة كان لها بالغ الأثر في تتمية جوانب الذات الاستثارية، حيث ان توظيف الوسائط المتعدة ساعد على زيادة دافعية الطلاب الى التعلم بشكل اكبر نتيجة احساسهم بالمتعة العقلية في التعلم ، واستخدام الأنثطة المرتبطة بالواقع ساءد الطلاب على كسر حاجز الجمود والتجريد ، وياتلالي تجاوز موضوعات المقر النظري الى التطييق العطي مما ساعد على 
معايثة المتعلم للأحداث المتعلقة بموضوعات الوحدة ، مما ساعد على تتمية قرة المتعلم وزيادة دافعيته للعمل في مجال السياحة بعد تخرجه والاتجاه نحو الاستثمار. وتتفق هذه النتيجة مع دراسة كلا من Desel (2014) Rol

Boca \& etc. (2012) التوصيات والمقترحات:

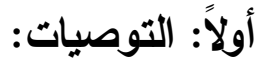

في ضوء ما أسفرث عنه نتائج البحث الحالي توصي الباحثة بما يلي ا -تصميم مناهج التعليم القني التجاري في ضوء نماذج الواقع الافتراضي. r -تعميم استخدام البرمجيات التعليمية المدعومة بالواقع الافتراضي في تدريس مادة الاقتصاد نظراً لطبيعتها الجافة. r-عقد دورات تدريبية لمعلمي العلوم التجارية على استخدام الواقع الافتراضي وتوظيف التكنولوجيا في التعليم. ـ -تدريب الطلاب المعلمين على وتصميم بيئات تعليمية الكترونية واستخدام التكنولوجيا في التريس. ه -تعميم فكرة الفصول التخيلية الافتراضية في كل المدارس لضرورة جدواها وأهمية كل منها في تتمية مهارات التفكير. ثنانياً: المقترحات: 
في ضوء نتائج البحث وتوصياته تقترح الباحثة الموضوعات التالية: 1 - تصميم مناهج التعليم الفني التجاري في ضوء نماذج التعليم الاكتروني

r- تصميم برنامج قائم على الأنثطة الاكترونية في مقر السكرتارية لتمية مهارات التواصل واتخاذ القرار لاي طلاب المرحلة الثانوية الفنية. r- اعداد برنامج تدريبي لمعلمي العلوم التجارية اثناء الخدمة، لتريبهم على تصميم الأنثطة والاختبارات الاكترونية. ؛ - تصميم برنامج تدريبي قائم على الأنثطة الاكترونية لعلاج صعويات التعلم في (الإحصاء-الرياضة المالية). ه - تصميم برنامج قائم على الأنثطة الاكترونية المتكاملة لتنمية مفاهيم الانخار وترشيد الاستهلاك لاى طفل الروضة. צ- تصميم استخدام الواقع الافتراضي المتكاملة لإكساب الأطفال مهارات وإدارة الأموال وتنمية اتجاهات الأطفال نحو المشروعات الصغيرة. V تنمية المهارات الحياتية والييئية من خلال تكنولوجيا الوسائط المتعدة في مادة الاقتصاد لاي طلاب المرطلة الثانوية الفتية.

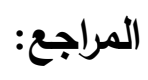

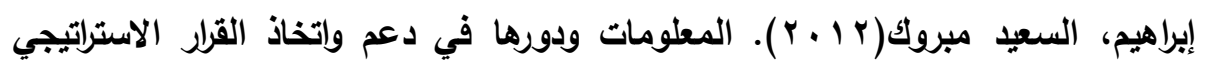
(القاهرة: المجموعة العربية للتنريب والنثر). 
ابراهيم، محمد أبو المعاطي (10 ب ب). برنامج قائم على تقتية الواقع الافتراضي لتمية

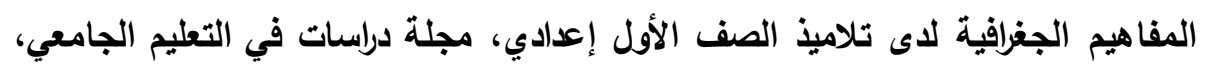
rq. - rs เ $r q \varepsilon$

الحوري، مدين وهنداوي، عمر والثرقاوي، صبحي (2009). إثر استراتيجية سونرو وسلاثر

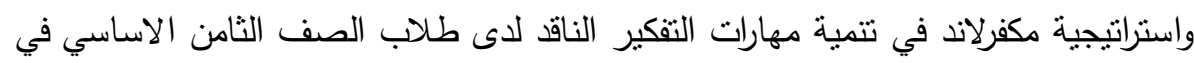
الاردن وتحصيلهم في مبحث الثاريخ، المجلة الاردنية في العلوم الاردنية، المجلد(ه)، العدد . rVO- rTrG(r)

خالد ، جميل (؟) (ب). أساسيات الاقتصاد الدولي. (عمان: الأكاديميون للنشر والتوزيع).

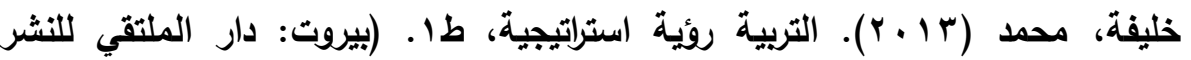
والتوزيع).

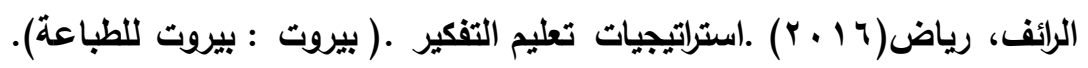
رشوان ، ايمان: الوقع الافتراضي مخلا لهيكلة التريس الفني.( دمثق : المجد للطباعة). الزيدات ، سامية محمد (2015). فاعلية استراتيجيات تعليم التفكير الناقد في التكريس الفني ، وعلاقتها بتنمية مهارات ما وراء المعرفة ويعض جوانب الأت. رسالة ماجستير (غير منشورة)، كلية التربية، جامعة الخليل.

سعادة، جودت احمد (2006). تدريس مهارات التفكير( مع الامثلة التطيقية) ط 1 ، ( عمان:دار الشروق للنشر والتتوزيع). سلام ، احمد عطية (2016) .وحدة رقمية في التربية الامانية لتنمية المعرفة العلمية والقدرة على اتخاذ القزار لاى الطلاب المعلمين بالثعب العلمية بكلية التربية ـ مجلة كلية

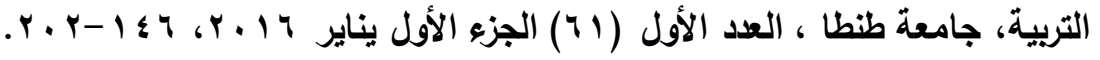


السلاموني، حنان (ع ا ـ ץ). فاعلية برنامج قائم على التعليم المدمج في تتمية المفاهيم الخاصة بالتجارة الاكترونية لاى طلاب المدارس الثانوية التجارية المتقدمة، مجلة كلية

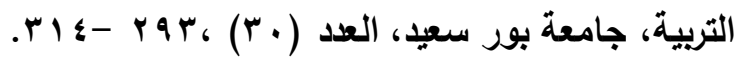

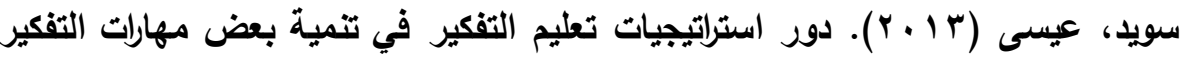
العليا اعتمادا على تكنولوجيا الواقع الافتراضي. ( لبنان : المركز الاستراتيجي لاراسات (التتمية).

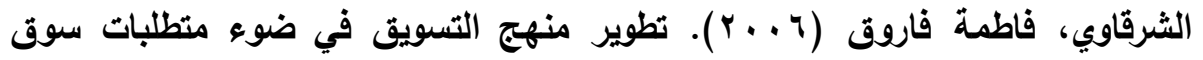
العمل. رسالة دكتوراه (غير منشورة)، كلية التربية، جامعة طنطا.

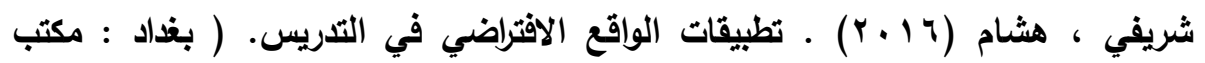

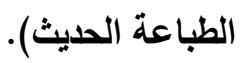

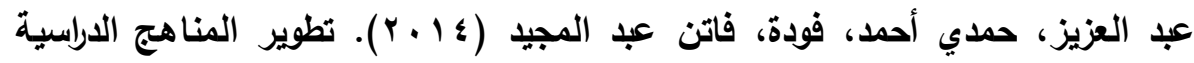
بالتعليم الفني التجاري في ضوء مهارات القرن الحادي والعشرين اللازمة لتلبية المتطلبات

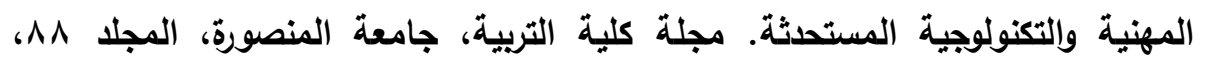

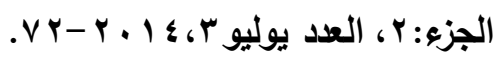

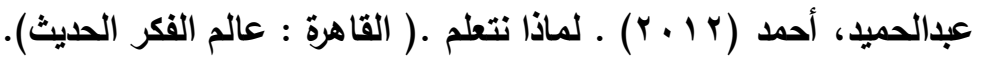
العرنوسي، فؤاد (11 • ب). تحديات الواقع الافتراضي، وتتمية مهارات ما وراء المعرفة في التعليم القني. (عمان: عمان للطباعة). عواد، ضيف الله (r ا ـ Y). دور الواقع الافتراضي في تنمية المهارات العليا للتفكير وتقدي الأات " ورقة عمل مقدة للمؤتمر التريوي السنوي بامشث، جامعة تشرين، ابريل.

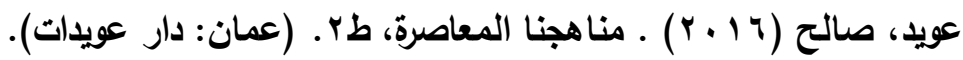
فودة، فاتن عبد المجيد (10 ب). استراتيجية مقترحة قائمة على الدمج بين الرحلات المعرفية عبر الويب ونموذج بوسنر للتعبير المفاهيمي وفاعليته في تعديل التصورات 
البليلة للمفاهيم الاقتصادية وتتمية عمق التعليم لاى طلاب المدارس الثانوية التجارية

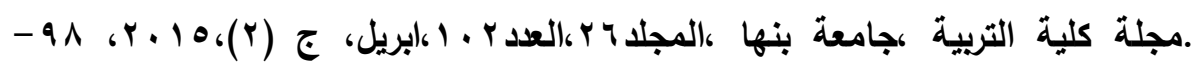
.175 القمش، مصطفي نوري والجوالدة ، فؤاد (2016). تعليم التفكير.(عمان: دار الثقافة للنشر والتوزيع). كامل، ثروت (1 ا • r) .الواقع الافتراضي · (عمان : دار عويدات). مايكل، رؤوف(7 1 • ץ). الدور الذهني لاستراتيجيات تعليم التفكير • (عمان: دار عويدات). مجمع اللغة العربية (q . . r). الاصدار (10). منظمة اليونسكو (r ا ـ r). توصيات المؤتمر الصين الدولي الثالث: تحقيق التحول بثأن التعليم والتدريب - بناء المهارات من اجل العمل والحياة. شنغهاي، ؛ 1 - 1 ابريل.

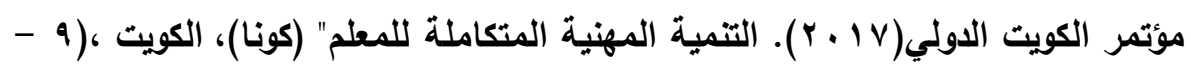

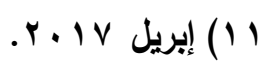

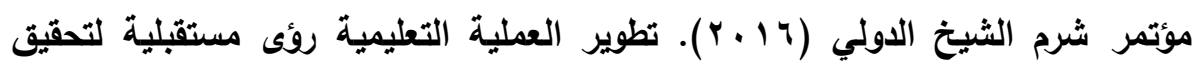
تنمية مستدامة. شرم الثيخ ، 1- 1- مارس.

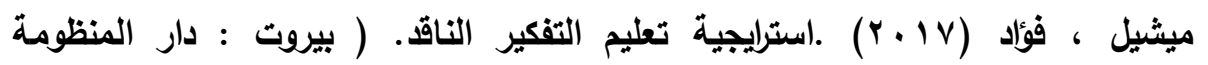
(التاريخية) نابلسي ، الحاج (V V + r) .التدريس وتكنولوجيا العصر .( بيروت : دار الصحوة).

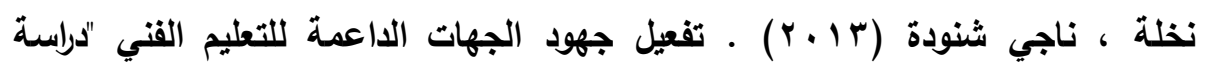

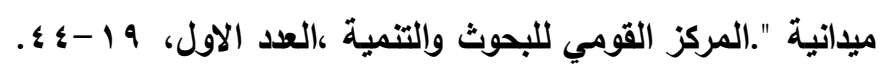
الواسطي، رياض(7 1 • ץ). التدريس الفني. (عمان : دار عويدات). 
Abari, O., Bharadia, D., Duffield, A., \& Katabi, D. (2017). Enabling high-quality untethered virtual reality. Proceedings of the 14th USENIX Symposium on Networked Systems Design and Implementation (pp. 531-544). Retrieved from https://www.usenix.org/conference/nsdi17 GS Search

Alexandros, M. (2010). The Development of Decision-Making Skills, Eurasia Journal of Mathematics, Science \& Technology Education, 2011, 7(1), 6373.

Chetle,C. (2016). Education As Creativity. ( London: mack well press).

Colin.W.L., Martijn,W.Z., Jaap, W. O., Michael L. W., Russell,S.(2008). Group-Level Self-Definition and SelfInvestment: A Hierarchical (Multicomponent) Model of InGroup Identification ,Journal of Personality and Social Psychology, Vol. 95, No. 1, $144-165$.

Davis, N.E. (2015). New Zealand's development of ultrafast broadband in schools including the largest nationwide school. In developing new indicators to describe digital technology infrastructure in primary and secondary education (pp. 67-70). Montreal, CA: UNESCO

Del Boca, D., Monfardini, C., Nicoletti, C,(2012). Self Investments of Adolescents and Their Cognitive 
Development. IZA Discussion Paper No. 6868. Available at SSRN: https://ssrn.com/abstract $=2158010$

Duel ,C.L.(2017).Funny Teaching.(London : Mack well press).

Ferandez,M.(2017,June1).Augmented Virtual Reality: How to Improve Education Systems Higher Learning Research Communications, 7(1), 1-15.

Fred ,P.L.(2008). All these causes. (London: tny press).

Fredrick,C.L.(2014). How to teach. ( London : merry press).

George,A.E.(2015). Mackferland Strategy.( London: kin Press,3Print).

Gisho,O.M.(2011).Applications Of Virsual Teaching. ( London: nero Press).

Kelley ,S.M.(2015). Development of High Thinking Skills. ( London : torri Press.1st Print).

Kelten,S.(2009). Teaching Approaches. (London: rauel Press). 
McFarland, A. M. (1985). Critical thinking elementary school social studies. Social Education, 49 (3), 277-280. Merret,T.(2006). High Thinking skills. ( London: man well press).

Rame ,A.(2013). Creative Teaching .( lodon :kjh press).

Schmalstieg , D. \& Höllerer, T. (2016). Augmented reality: Principles and practices. Boston: Addison Wesley. https://doi.org/10.1145/2897826.2927365

Soo, D. (2016, August 2). A new age of VR involving all five senses. International Society for Presence Research. Retrieved from https://ispr.info/2016/08/02/a-new-age-of-vr-involving-all-fivesenses

Vany, C.M.(2017). Technology as Senior (London: nhyfd Press).

Varshney ,A., Eric, K., Catherine,P.(2018). Virtual memory palaces: immersion aids recall, was published online in the journal Virtual Reality on May 16, 2018. Retrieved from https://ispr.info/2016/08/02/a-new-age-of-vr-involving-all-five- 
Yiyu,O.Cai,(2017). Virtual Reality Technology Enhanced Learning, Nanyang Technological University (SINGAPORE). Conference: International Conference on Education and New Learning Technologies, 12-14 March. 